\title{
Structure, Formation, and Biological Interactions of Supported Lipid Bilayers (SLB) Incorporating Lipopolysaccharide
}

\author{
Palak Sondhi, Dhanbir Lingden and Keith J. Stine * \\ Department of Chemistry and Biochemistry, University of Missouri-Saint Louis, Saint Louis, MO 63121, USA; \\ ps2f7@mail.umsl.edu (P.S.); dlv4f@mail.umsl.edu (D.L.) \\ * Correspondence: kstine@umsl.edu; Tel.: +1-314-516-5346
}

Received: 24 August 2020; Accepted: 12 October 2020; Published: 14 October 2020

check for updates

\begin{abstract}
Biomimetic membrane systems play a crucial role in the field of biosensor engineering. Over the years, significant progress has been achieved creating artificial membranes by various strategies from vesicle fusion to Langmuir transfer approaches to meet an ever-growing demand for supported lipid bilayers on various substrates such as glass, mica, gold, polymer cushions, and many more. This paper reviews the diversity seen in the preparation of biologically relevant model lipid membranes which includes monolayers and bilayers of phospholipid and other crucial components such as proteins, characterization techniques, changes in the physical properties of the membranes during molecular interactions and the dynamics of the lipid membrane with biologically active molecules with special emphasis on lipopolysaccharides (LPS).
\end{abstract}

Keywords: Langmuir-Blodgett; lipopolysaccharides; supported bilayers; monolayers

\section{Introduction}

The multifaceted role of lipid membranes can be seen in physiological processes such as cell-cell adhesion, the transport of molecules and ions across membranes, triggering of signal transduction pathways, and in cell metabolism. All these crucial roles of biological membranes prompted the development of artificial lipid membrane models to diversify their scope in the field of biosensor development, drug testing, drug discovery, or as simplified model systems for studying the dynamics of the biological membrane [1]. The cell membrane is a research frontier that has been explored for many years and has never failed to intrigue scientists with its prospects for future insight. Model membrane chemistry began with observations of the spreading of oils and fats on the water surface dating back to the eighteenth century. The observations were explored further in 1917 by Irving Langmuir in terms of measuring the surface pressure exerted by the monomolecular layer as the lipid or amphiphilic molecules spread on the water surface. Langmuir further calculated the area per lipid molecule and inferred the flexibility of the hydrocarbon chains [2]. Natural cell membranes are complex structures and pose many problems when studied in their native form. Therefore, simpler lipid model systems are desirable to study cell membrane components and their interaction with biological molecules. Simple cell membrane models span from monolayers at the air-water interface to solid-supported lipid bilayers with ever-growing new formulation techniques involving tethering, hybrid membranes, intact liposomes, use of nanostructures, polymer cushions and many more ideas [3]. There have been immense contributions in the field of mimicking cell membranes via various unique methods. A timeline showing these developments is illustrated below in Figure 1. 


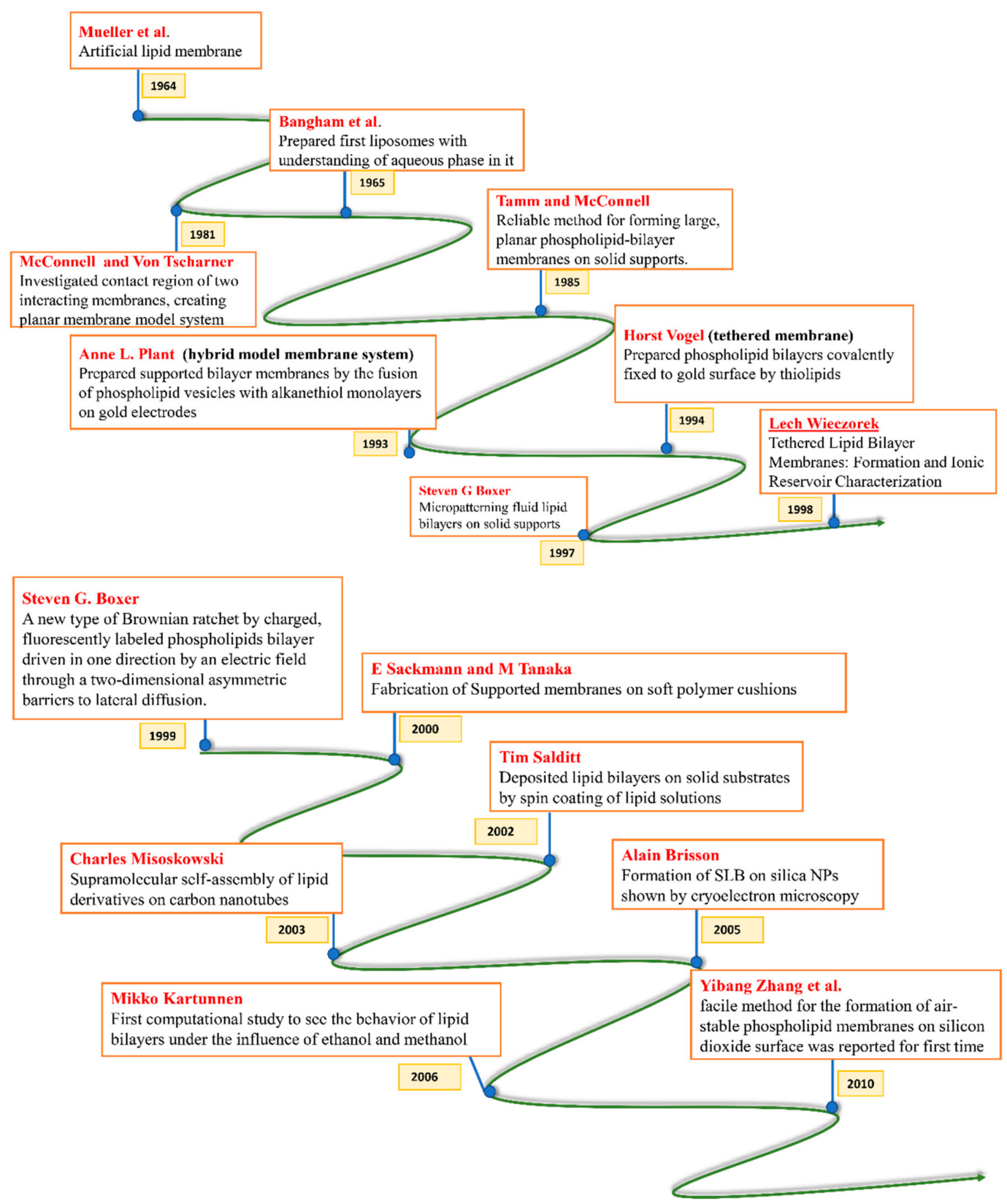

Figure 1. Timeline showing many of the important efforts to mimic the biological cell membrane.

In 1964, Mueller et al. described a type of artificial lipid membrane for the first time called the black lipid membrane (BLM). There are two well-known procedures for the construction of BLMs which include painting of a lipid solution over an aperture and the formation of a folded bilayer. The three main components of BLM are the lipid bilayer, a thicker annulus, and the microlens [4,5]. This experimental lipid bilayer membrane became an attractive tool for the study of the physicochemical properties of cell membranes that encompass the permeability of substances of physiological interest [6]. In 1965, Bangham and coworkers came up with a better understanding of a standard method for producing idealized multilamellar vesicles (MLV), or liposomes, which involved the dissolution of a lipid in an organic solvent such as chloroform followed by vacuum drying to produce a thin film on the bottom of a round-bottom flask. The subsequent addition of aqueous solution aided by vortexing until the dry film was removed completely from the wall of the flask resulted in the formation of liposomes [7]. Bangham and collaborators prepared the first liposomes which were artificial vesicles bounded by a lipid bilayer. They concluded that liposomes contained an aqueous 
inner phase and would rapidly become structures of great importance for studying the permeability of membranes [8]. Membrane-membrane interactions are of crucial interest to many biochemists and biophysicists. In recent years, model membranes have been prepared by various approaches to mimic cell-cell interactions. A planar membrane model system was developed in 1981 by Von Tscharner and McConnell to investigate the contact region between two interacting membranes using microscopy [9]. Planar model membranes such as supported lipid bilayers and tethered membranes have served as useful tools for investigating complex functions performed by biological membranes. The complexity of real membranes can be scaled down to simpler model membranes where the functions and interactions of the components can be explored. Tamm and McConnell, in 1985 reported the concept of supported lipid bilayers which were relatively easy to prepare and accessible to analytical techniques such as fluorescence microscopy [10]. Forging ahead with the idea of supported lipid membranes, Plant in 1993 created self-assembled alkanethiol monolayers directly on gold surfaces that gave a hydrophobic surface for the formation of stable lipid bilayers via a vesicle fusion process to produce a hybrid system. This model system mimicked Langmuir-Blodgett (LB) films and BLMs with the additional advantages of ease of preparation and reproducibility, long-term stability and formation on an electrically conductive support. The structural integrity of bilayers formed through this approach can be analyzed using electrochemical methods [11].

Unfortunately, supported lipid bilayers are too rigid to incorporate intrinsic membrane proteins in an active form. This comes from the fact that they are directly resting on the solid support without any space for water which is required for proper folding of the extra-membranous parts of a membrane protein. Therefore, a new concept was introduced in 1994 which described the covalent attachment of lipid bilayers to a solid support such as gold surfaces by sulfur groups. The fundamental requirement for a membrane protein to function properly is to be surrounded by water on both sides of the membrane. This requirement was fulfilled by using synthetic lipids containing spacer groups such as oligoethylene glycols of variable length [12]. A great amount of work was done on lithographically patterned surfaces. Steven G. Boxer and coworkers developed the art of patterning supports for lipid bilayers and achieved success in this field which included the development of micrometer-scale patterns in surface wettability and microcontact printing of bilayers. Patterns were created resembling those of living cells thereby creating bilayer membranes on spatially and chemically distinct libraries of molecules on hydrophilic oxidized silica. This was a novel platform useful for studying the physical and biological properties of membranes [13]. During the 1990s, there were challenging problems in the field of chemistry and physics addressed in terms of the ability to design and build nanostructured architectures through self-assembly of monolayer, bilayer, and multilayer membranes. Although supported BLMs have gained a lot of attention in the past they do suffer from a crucial drawback of not possessing an ionic reservoir on both sides of the membrane which limited examination and study of membrane transport functions. To develop a biomimetic bilayer membrane of practical importance, a tethered bilayer membrane was produced by Lech's lab in 1998 that possessed characteristics including an insulating lipid core, an ionic reservoir on each side of the membrane, high mechanical, chemical, and biological stability and ease of production. Their system closely resembled the classical BLM with higher stability combined with ease of production [14].

When an asymmetric periodic potential is applied to Brownian particles, they undergo net directional motion even if the spatially averaged force is zero. The phenomenon of the Brownian ratchet has attracted great interest in varied fields of science and technology. Brownian ratchets were considered in the context of biological systems by Boxer in 1999 using a two-dimensional solid-supported fluid lipid bilayer membrane. The geometrical Brownian ratchet also had the potential to separate mixtures of different lipids or membrane proteins such as integral proteins that are difficult to handle, with the advantage of their being separated continuously in their native environment [15]. With all the advancements in the field of lipid bilayer fabrication, the idea of thermodynamically and mechanically stable stratified polymer-lipid composite films was introduced in 2000 by Tanaka and Sackmann. The design of biocompatible interfaces was of practical and scientific importance. 
Soft polymers paved the way for the stress-free immobilization of cells and cell receptors and this model has helped to investigate the principles of cell adhesion and growth [16]. Largely aligned and homogeneous bilayers have been prepared by a new strategy wherein stacks of a small and well-controlled number of bilayers on a substrate have been assembled. This method of spin coating involved two rotating steps. The first slower rotation helped in spreading the lipid solution uniformly on the surface while the second rotation is for quick drying and ejection of the spare solution [17].

Nanomaterials have shown immense potential for use as the support for lipid membranes. Carbon-based nanomaterials were used for the first time as supports for the supramolecular self-assembly of lipid derivatives due to unique structural, mechanical, and electrical properties [18]. A combination of materials science with its advanced technologies and biological sciences with elaborate molecular architectures has proven to be quite promising. Silica nanoparticles were experimented on for use as solid supports for lipid bilayers. Nano-supported lipid bilayers (SLBs) were created using adsorbed lipid vesicles over silica nanoparticles. Cryo-transmission electron microscopy (cryo-TEM) was used for the first time to characterize the material. Nanoparticles covered with SLBs combined the properties of metal oxide and lipid bilayers [19]. The then futuristic idea of laying down intact liposomes on the surface changed the whole field. In the technique, liposomes were deposited from solution into an array of microwells that had been etched on a surface. Neutravidin-biotin chemistry was used to attach liposomes to the well. The entire structure was used to form a membrane protein microarray for multiplexed screening applications [20]. Recently, air-stable phospholipid bilayers have been designed using a polymer surrounding phospholipid membrane on a silica wafer. Air stability was attained using poly (ethylene glycol) (PEG) shielding and a chitosan cushion [21]. There are several methods for the construction, stabilization, and functionalization of artificial lipid membranes. Each platform has its pros and cons for serving the respective future scope of the intended research. Several synthetic schemes are described below.

\section{Different Methods of Formation of Artificial Lipid Membrane Models}

A multitude of methods has been proposed to create biomimetic models of membranes including Langmuir-type approaches (Langmuir-Blodgett or Langmuir-Schäfer deposition) and spreading of vesicles on surface-modified supports. The latter represents an attractive and simple route towards the formation of solid-supported lipid bilayers which involve self-organization steps from vesicle adsorption to their rupture and finally spreading into planar membranes [22]. The manufacturing of lipid membranes is still an active area utilizing the knowledge of lipid structure and function along with the available techniques [23]. Various strategies used to synthesize lipid membranes are discussed below.

\subsection{Liposomes to Lipid Bilayer-Direct Vesicle Fusion}

Biological model membranes have been studied for the past few decades with liposomes and black lipid membranes being the predominant model systems. The method of fusion dates back to the 1980s when membrane-like structures were produced by transferring liposomes to both hydrophilic and hydrophobic surfaces. The sequence of events starting from adsorption to the final bilayer or monolayer formation can be influenced by various parameters such as the surface, the size and lipid composition of the liposomes along with various experimental conditions. It is also essential that the membrane proteins acquire the same orientation after the formation of the membrane. The development of the atomic force microscope (AFM) has helped researchers to observe events such as structural changes via enzymatic degradation by sequential imaging in situ under specific conditions [24]. Unilamellar liposomes of diameter 200-300 nm can be prepared from lipid mixtures using the detergent depletion technique. The strategy involves the dissolution of lipids in an organic solvent such as chloroform followed with drying the solvent by flushing nitrogen gas. After complete drying under vacuum, the vessel has to be warmed and preheated in buffer along with surfactant added to dissolve lipids and form mixed micelles. The dispersion with a specific phospholipid concentration is then recirculated 
over the support at a constant flow rate for a couple of hours at room temperature. For further measurements, the support has to wash several times with water and dried under a stream of nitrogen. The success and ease in forming lipid bilayers using liposome fusion on a solid support depends on type, structure, and cleaning of support, geometry, and flow dynamics in the fusion cell [25]. Work has been done to study the structural integrity of unilamellar liposomes upon freezing and thawing. Closely looking into the synthesis as described above, it can be concluded that mechanical agitation is enough to overcome the transition barrier from a suspension of lipid into a suspension of small unilamellar vesicles. However, freezing and thawing are responsible for the partial reversal of this transition. In the study, this loss of integrity was monitored by measuring the change in turbidity, and by loss of energy transfer between fluorescent probes incorporated in the bilayer membrane [26].

There is an ongoing search for simpler model systems with the incorporation of all the essential components of real cell membranes associated with biological functions. Recently, work has been done to show that lipid bilayers can be prepared by a method where liposomes are adsorbed on a suitable modified surface. It is an essential requirement that the transmembrane proteins do not come in contact with the substrate as this results in pinning and loss of function. Therefore, tethering the lipid bilayers using a short hydrophilic spacer of PEG on a graft copolymer, poly(L-lysine)-graft-poly(ethylene glycol) (PLL-g-PEG) solved the problem as seen in Figure 2. A surface with negative potential is suitable for the self-assembly of the polymer by a simple dip-and-rinse method. Simple lipomimetic tethers were made using quaternary ammonium compounds with the chain end-functionalized with PEG to interact with the membrane. This method results in a controlled deformation of liposomes by tuning the number of tethers [27].

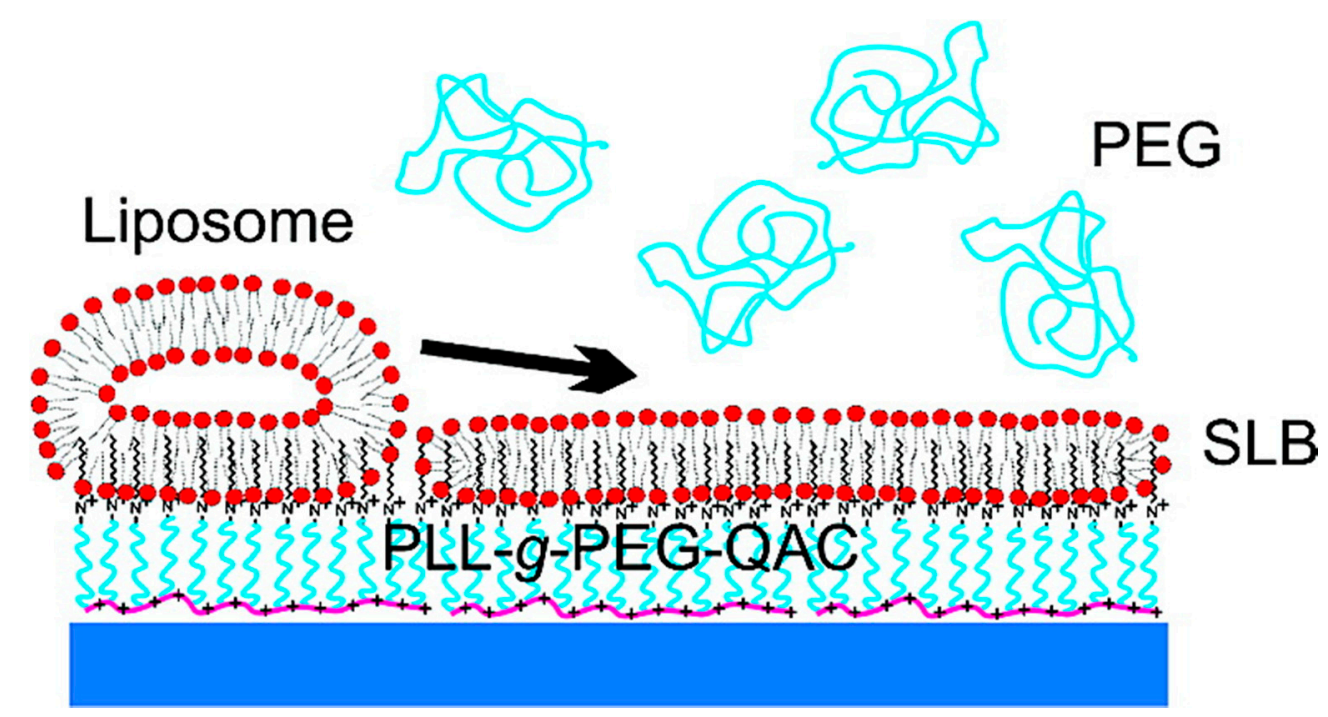

Figure 2. Schematic of the PLL-g-PEG-Quaternary ammonium compound (QAC) platform for liposome capture and induced rupture to form supported lipid bilayer (SLB) (Adapted with permission from reference 27. Copyright 2009 American Chemical Society).

A novel and highly reproducible method of preparing arrays of intact liposomes of diameter $1 \mu \mathrm{m}$ into microwells that have been etched on the surface and have the appropriate size to incorporate only one liposome each. The conjugation used here was the essentially irreversible binding between biotin and neutravidin. Surface functionalization of liposomes and amine-modified self-assembled monolayers was done using biotin. Liposomes were made to react to the bottom of the well due to the presence of neutravidin adapter linkages. The area around the wells was made inactive using PEG self-assembled monolayers that also prevent the adsorption of liposomes. All the steps were affirmed using confocal microscopy involving fluorescent dye attached to neutravidin, a water-soluble dextran-Texas red dye in the liposome interior, and a lipid dye embedded in the bilayer [20]. 
The technique that paved a way toward chip-based integrated membrane protein biosensing was self-assembly of nanopore-spanning lipid bilayers (nps LBs). This approach exploits the fusion process of liposomes and is done directly on nanopore patterned silicon nitride substrates. The formation of solvent-free nps LBs is possible when criteria such as minimum liposome to pore diameter ratio, high curvature pore edges, and the selection of appropriate substrate and liposome composition to have high surface adhesion energy, are met [28]. Liposomes are the common starting point for the preparation of supported lipid membranes which in turn are used as cell membrane mimics for a wide variety of applications such as to investigate membrane dynamics, protein-lipid interactions, and as supports for cell culture. It is necessary to emphasize at this point the importance of lipid phase transition temperature and liposome size as both the factors are important for the preparation of cell membrane mimics and for designing temperature responsive material coatings. In the study, it was shown that smaller liposomes ( $\sim 90 \mathrm{~nm}$ in diameter) have low stability and ruptured readily above the liquid phase transition temperature whereas larger liposomes $(\sim 160 \mathrm{~nm}$ in diameter) stayed intact. It was further demonstrated that the viscoelastic properties and the changes seen in it can be used to evaluate liposome permeability as the temperature approaches the phase transition point [29].

\subsection{Monolayers at the Air-Water Interface}

Lipid films at the air-water interface are used as model systems to study the physical properties of membranes and lipid interactions with other important components of biological membranes. Most of the studies using monolayers of fatty acids and lipids at the air-water interface are undertaken using a trough and a rhombus assembly on the stage of a microscope. Surface-pressure is measured using a Wilhelmy plate attached to a torsion balance [30,31]. Insoluble monolayers can be investigated using the Langmuir trough, which is used to generate pressure-area (П-A) isotherms whose kink and plateau analysis provides an easy route to learn about the phase and ordering transitions experienced by the monolayer. The procedure to obtain an isotherm of the given monolayer is to spread the film, evaporate the solvent and then compress the film using a moving barrier at modest speeds [32].

Current biomimetic models postulate non-random lipid mixing in each leaflet of the bilayer giving rise to microdomains with special physical and functional properties. Analysis of interfacial potential and surface pressure as a function of the cross-sectional molecular area can give a clear picture of the hydrocarbon chain ordering, lateral compressibility, and dipole effects of the lipid layer upon biological interactions [33]. Using this approach, the condensing effect of cholesterol on the liquid-expanded phase of different molecular species of galactosylceramide (GalCer) with homogeneous acyl chains was studied. Incorporation of cholesterol reduced the trans-gauche isomerization about the $\mathrm{C}-\mathrm{C}$ bonds in liquid-disordered acyl chains of GalCer resulting in significant condensation due to gain in van der Waals forces between the molecules [34].

Additional techniques were developed to further probe the state of monolayer films. Fluorescence microscopy revealed the presence of domains with fascinating morphologies. The immiscibility of the two liquid phases results in a monolayer with domains formed spontaneously at the air-water interface with typically in the few-tens of microns size range [35]. Lipid domains can be used to sense chemical events at the air-water interface due to resulting critical shape transitions [36]. Long-range electrostatic forces are seen to be present between the molecules in monolayer films at the air-water interface. These forces acting between molecules within and between the domains compete with line tension at the domain boundary giving rise to shape transitions [37].

In recent years chemical bottom-up processes have attracted much attention as they make use of self-assembly of small building blocks that ultimately give rise to materials with specific nanostructures useful for material separations, sensing, or catalysis. Self-assembly often uses interfacial processes and therefore, a combination of the two has given interesting materials such as self-assembled monolayers (SAM), Langmuir-Blodgett films (LB), and layer-by-layer (LbL) techniques [38]. In the field of biophysics and material science, exploring the structural aspects of the microscopic interface between the molecular layers of amphiphilic molecules and an aqueous compartment is crucial. Monolayers 
floating on an aqueous subphase are an excellent model for the investigation of such interfaces. Combined neutron and X-ray reflectivity measurements initially developed for application to many thin film systems were a breakthrough for the structure investigation of the floating monolayers [39]. In 1994, Langmuir films of antibodies were gaining interest due to their wide-ranging prospective application in the field of biosensors. Assembling immunoglobin $\mathrm{G}$ films at the air-water interface has been carried out by Langmuir-Schaefer techniques aided by the high stability coming from large amounts of S-S bonds inside the structure. In the study, ellipsometry was used to measure film thickness and film molecular density was addressed using fluorescence measurements [40]. Pioneering works of Langmuir including monomolecular layers at interfaces have been investigated theoretically and experimentally. More recently, two-dimensional layers of long polymer chains at interfaces have been worked upon using various strategies such as grafting the polymer chains by one end, adsorption onto the interface, forming monolayers of diblock polymers at the liquid-liquid and air-liquid interface [41].

Enzymatic processes involving chiral molecules and condensed monolayers of such molecules were investigated to explore chirality effects at the air-water interface. A study where the homochiral effect and the molecular structure of LB films comprising of a pure enantiomeric monolayer of $N$-octadecanoyl-L-alanine to study the homochiral behavior have been reported [42]. When the homochiral interaction is strong, it is possible that D-rich or L-rich domains would separate out from the racemic mixture thus breaking the chiral symmetry. Such phase separation is indicative of stronger interaction between enantiomers of the same chirality than between those of opposite chirality. This phenomenon is analogous to prebiotic chiral segregation with homochiral preference [43]. Molecular theories are the most promising when chirality induced features of monolayers are addressed. It is believed that the molecular structure of the amphiphiles determines the molecular arrangement and several features of the domain shape, which is proven by experimental results from isotherm studies, optical measurements, and diffraction techniques. Chiral discrimination effects in chiral monolayers are manifested in various ways such as noticeably different features of the isotherms, handedness of the shapes of the domains formed in the condensed phase, or the differences in the lattice structures of the enantiomer and racemic mixture [44].

Monolayers at the air-water interface have been used as a biomembrane model tuned by mechanical compression for studying the intermolecular interactions of a guest with the host molecule. A model employing a polycholesteryl-substituted cyclen complex host molecule and its successful inversion of enantioselectivity in amino acid recognition by applying lateral pressure to the monolayer at the air-water interface was reported. Through this model mechanical control of enantioselectivity in amino acid recognition has been seen for the first time where a small difference in amino acid structure resulted in remarkably differing selectivity which was analogous to the delicate functions of enzymes and receptors in living beings [45]. Quantitative studies using the quartz crystal microbalance (QCM) have been used to detect interactions of proteins with phospholipid monolayers. A QCM system was attached horizontally to the lipid monolayer at the air-water interface to detect quantitatively the interactions of small and hydrophobic mellitin and relatively large protein of $\beta$-globulin from the change of frequency at the interface, mass change after air drying, and determining the change in the surface pressure (П) value of the monolayer [46].

It is also possible to gather information regarding the molecular arrangement within monolayers using techniques such as grazing incidence X-ray diffraction (GIXD), Fourier transform infrared (FTIR) spectroscopy in the method of infrared reflection absorption spectroscopy (IRRAS), and Brewster angle microscopy (BAM). GIXD can give information of the two-dimensional lattice structure of monolayers and the molecular orientation. IRRAS, generally useful for thin coatings on reflective surfaces, can be sensitive enough to be applied at the air-water interface to give information on hydrocarbon chain ordering and on the presence of specific functional groups. X-ray studies were crucial for giving an insight into the change in the orientation of lipid molecules upon enzyme interaction thereby producing structural changes in the inner domains. FTIR spectroscopy in this case gave information about the reaction products which include the fatty acid that stayed at the interface and lysophospholipid 
that partially dissolved into the subphase. The BAM method provided a new possibility for direct visualization of the domain structure of Langmuir monolayers without the need for use of fluorescent probes. Moreover, it allowed observation of the long-range orientational order of a phospholipid in a monolayer which induces optical anisotropy due to tilted aliphatic chains. The technologically crucial enzyme phospholipase was employed in the study to visualize the correlation of changes in its catalytic activity with the molecular domains in the monolayer [47].

A great deal of experimental work has been done to exploit Langmuir monolayers at the air-water interface to mimic biological complexity by creating nucleolipids for molecular recognition studies. Nucleolipid monolayers at the air-water interface mimic a single nucleic acid strand interacting with the complementary bases in the subphase and were studied after Langmuir-Blodgett transfer with molecular spectroscopy techniques involving ultraviolet-visible (UV-Vis) spectroscopy on quartz plates, transmission FTIR applied to $\mathrm{CAF}_{2}$ substrates, and surface-enhanced Raman scattering (SERS) on silver-coated glass substrates [48]. Recently, attention has been given to the major role of cholesterol in determining drug-cell membrane interactions. Work has been done to investigate the interactions between the guest molecules and cholesterol-containing membranes. For instance, paclitaxel an antineoplastic drug experiences enhancement in its intermolecular interaction with dipalmitoylphosphatidylcholine (DPPC) monolayers in the presence of cholesterol [49].

Since the early 1990s, there was a growing interest in the utilization of Gemini surfactants comprising two amphiphilic moieties with a rigid or flexible spacer group. The spacer group with different length, flexibility, and chemical nature will pose a different impact on the solution properties of aqueous surfactants and at the air-water interface. $\Pi-A$ isotherms of an increasing spacer group length shifted the curve towards the right indicating an increase in molecular area with constant surface pressure [50]. Furthermore, Gemini surfactants possess superior properties in the field of gene therapy in terms of lower critical micelle concentration and lower levels of toxicity compared with monomeric surfactants showing transfection efficiency. Gemini surfactant/ds or ssDNA complex monolayers at the air-water interface have been studied showing the relevance of spacer groups in controlling the morphologies of LB films and the interaction of DNA with the liposomes leading to compaction of nucleic acid crucial for obtaining high transfection efficiency [51].

Surface pressure-surface area isotherms can be used to infer molecular-level information about structural changes during the compression of an insoluble monolayer at the air-water interface. In a recent study, it was shown that the lower part of the isotherm was shifted towards the right (to higher molecular areas) upon varying the compression rate for a DPPC (a major component of pulmonary surfactant) at the air-water interface [52]. Protein structures at the air-water interface during compression-expansion can be well characterized using Brewster angle microscopy (BAM) as the adsorbed proteins at the air-water interface do not form crystalline-like domains. Results from the study of relative reflectivity versus surface pressure with $\beta$-casein monolayers reflected homogeneity in film thickness and isotropy [53]. A variety of interfacial processes such as chain ordering of lipid tail groups, phase behavior of a monolayer and fundamental issues including chain orientation, conformation, and head group hydration at the air-water interface have been studied using sum-frequency generation (SFG) spectroscopy which is a vibrational technique based on a second-order non-linear optical process [54].

\subsection{Langmuir-Blodgett Type Approaches}

The Langmuir-Blodgett (LB) transfer technique is a well-established method that dates to 1917, pioneered by Irving Langmuir and Katherine Blodgett to prepare supported monolayers, bilayers and multilayers. The LB method is widely used for creating supported monolayers and bilayers to serve as model membrane systems of controlled composition and physical state given that the precursor monolayers can be spread on the water surface with precisely controlled composition and can be transferred to a substrate at a set surface pressure corresponding to a desired physical state. The monolayer of lipid molecules at the air-water interface is to be compressed using a moving barrier 
to control the lipid phase. Lipid films are then transferred onto solid substrata using either LB or Schaefer transfer method [55]. Katherine Blodgett expanded the method to multilayers with repeated dipping of the substrate through the air-water interface [56]. A diagram for bilayer deposition by various techniques as shown clearly in Figure 3. Successive single layers of molecules of various stearates along with their optical properties have been described in detail. The thickness per layer of barium stearate was found to be $24.40 \AA$ with $1-3 \%$ of discrepancy seen in the spacing due to the presence of foreign substances in the water [57]. Phospholipid bilayers have been formed on various substrates such as glass, quartz, and silicon surfaces by transferring monolayers at a pressure of approximately 40 dyne $\mathrm{cm}^{-1}$ from the air-water interface to the solid substrate [9]. It is very important to transfer a monolayer formed at the air-water interface onto a solid substrate for advancement in the study of monolayers and thin films.

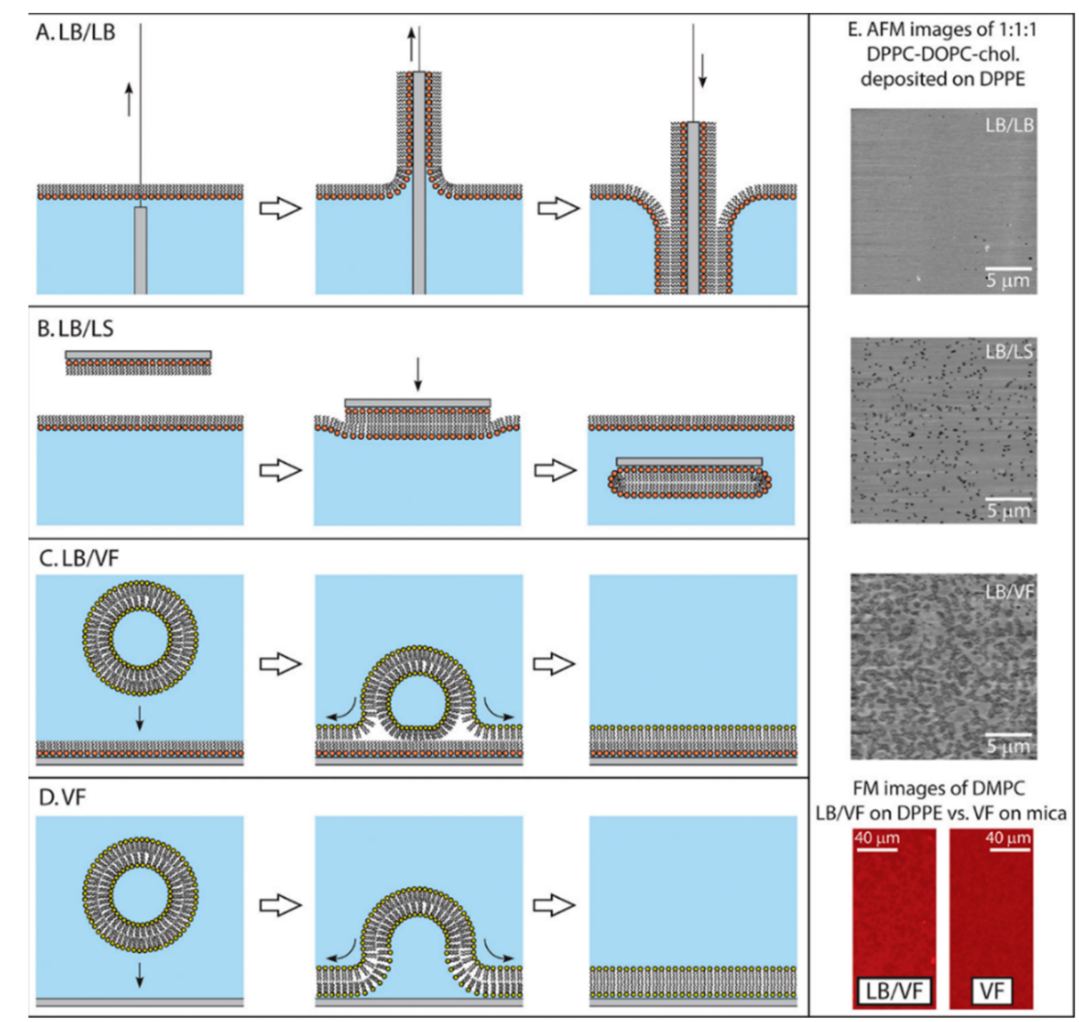

Figure 3. (A) Schematic Langmuir-Blodgett (LB) deposition of solid-supported bilayers. (Left) After the substrate has been immersed, lipid is deposited on the air-water interface and compressed to the desired surface pressure. (Center) The substrate is drawn out of the subphase perpendicularly to the monolayer at the air-liquid interface to deposit the inner leaflet. (Right) To deposit the outer leaflet layer, the substrate is then lowered through the interface. (B) Langmuir-Schaefer (LS) method to horizontally deposit the outer leaflet onto a substrate-supported inner monolayer leaflet. (C) Vesicle fusion (VF) on an LB-deposited monolayer. (D) Vesicle fusion directly onto a clean hydrophilic substrate. (E) The top three images are $20 \mu \mathrm{m} \times 20 \mu \mathrm{m}$ atomic force microscopy (AFM) topographs of 1:1:1 dipalmitoylphosphatidylcholine (DPPC)-dioleoylphosphatidylcholine (DOPC)-cholesterol SLBs deposited via LB or LS onto a 1,2-dipalmitoyl-sn-glycero-3-phosphoethanolamine (DPPE) inner monolayer LB deposited at a surface pressure of $45 \mathrm{mN} / \mathrm{m}$ on mica or by vesicle fusion. The LB and LS techniques on the outer layer were performed at a pressure of $30 \mathrm{mN} / \mathrm{m}$. The bottom images show fluorescence microscopy (FM) of 1,2-dimyristoyl-sn-glycero-3-phosphocholine SLB deposited as an asymmetric (on DPPE) vs. symmetric bilayer on a glass substrate using VF. (Reproduced with permission from [56], copyright 2018 American Chemical Society). 
Microscopic and spectroscopic tools are adapted and used for characterizing the structural organizations of the films such as BAM, UV-vis reflection spectroscopy, QCM, FTIR, SERS, X-ray photoelectron spectroscopy (XPS), and so on. The quality of the film deposition can be described by evaluating the transfer ratio (TR) of the substrate surface. The transfer ratio is the ratio of the area of the monolayer removed from the air-liquid interface to the area of the substrate surface deposited during the process of film deposition. TR equals 1 for an ideal transfer. The lateral surface pressure can have a strong effect on the TR values and hence on the quality of the film-transfer. The film transfer can be confirmed by observing the change in the roughness of the substrate surface as compared to the clean substrate surface. A drop in the surface pressure of the interface is often observed after the transfer of the films onto the substrate surface although the goal is to maintain a fixed pressure during LB transfer. The uniformity of the film surfaces can be studied by using microscopic and spectroscopic tools such as scanning electron microscopy (SEM), TEM, and AFM. These Langmuir techniques have widely been used to fabricate the lipid bilayers. The studies on lipid bilayers are very important to provide insight into the structural organization, dynamics and functionalities of bio-membranes, interactions between the membranes, diffusion of lipids and proteins, formation and characterization of in vitro model of bacterial cell envelop, and mimicking the bilayers in vesicles, and so forth [9,58-65]. It was reported that structural changes in lipid monolayers occur during LB transfer due to monolayer/substrate interactions. During the slow transfer, the domain-free gap was observed due to substrate mediated condensation of the monolayer in the moment of its deposition [66].

\subsection{Spin-Coated Lipid Bilayers and Their Characterization}

Interaction between membranes and biological molecules with an emphasis on biochemical and biophysical aspects under well-controlled conditions can be very well understood with the knowledge of solid-supported lipid bilayers. Several routes have been explored for the preparation of solid-supported bilayers such as vesicle fusion, Langmuir-Blodgett, and Langmuir-Schaeffer, and spreading from organic solutions. Studies have shown the importance of thermal stability and orientational alignment of the layers on the solid support. Spin coating is a valuable technique for preparing stacks of small, uniform, and well-oriented bilayers on support [17]. This method is useful for preparing multiple bilayers oriented on a solid substrate. With access to a spin coater, the creation of the thin film of stacked bilayers is a fairly straightforward procedure. In this technique, a drop of solution for making the coating is added onto the substrate and the substrate was rotated until the solvent evaporated to produce a uniform biomimetic layer suitable for investigations with X-ray reflectivity. It was found that the number of bilayers varied linearly with change in lipid concentration and upon hydration, the stability deteriorated [67].

An alternative to obtaining dry, air-stable, and high-quality lipid multilayers is the use of spin-coating techniques. This low-dimensionality system is defect-free and gives rise to morphologically stable lipid layers in dry air conditions [68]. The ultrathin dry dioleoylphosphatidylcholine (DOPC) layer's topography in spin-coated samples has been studied in different concentrations of lipid in the coating solution is represented in Figure 4. High-resolution techniques such as AFM have been used for studying domain formation and lateral lipid organization. A study has been conducted to optimize the homogeneity and thickness of dry multilayered lipid films using a combination of vesicle adsorption and subsequent spin-coating and further using AFM for extracting details on the microscopic level. AFM studies have shown that the homogeneity and thickness of lipid films can be altered substantially by varying the concentrations of vesicle suspension, the time and temperature used for adsorption, and the applied spin-coating sequence [69]. 

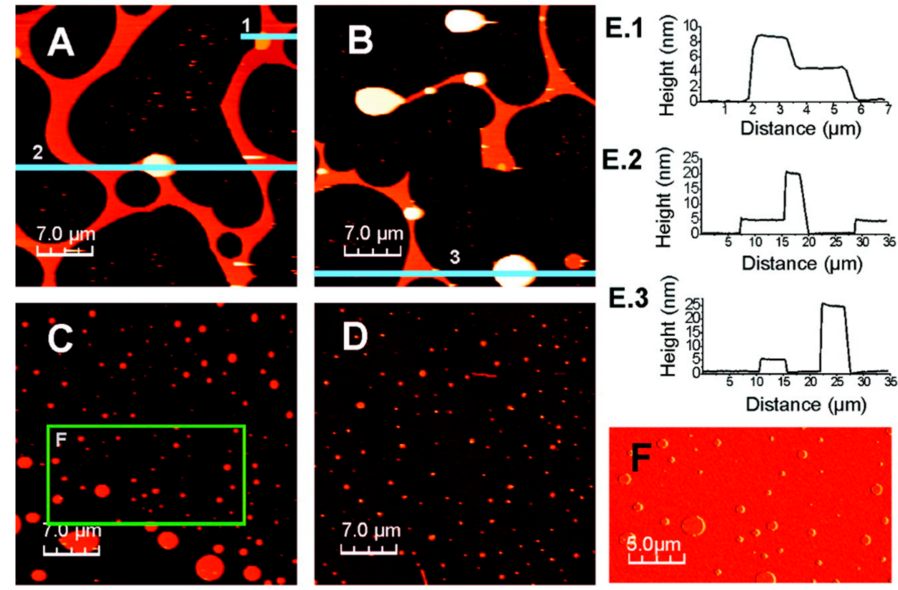

Figure 4. AFM topography images of spin-coated samples of DOPC in air prepared with different concentrations of lipid in the coating solution in the range $0.1-1 \mathrm{mM}$. (A) $0.75 \mathrm{mM}$, (B) $0.5 \mathrm{mM}$, (C) $0.25 \mathrm{mM}$, and (D) $0.1 \mathrm{mM}\left(35 \times 35 \mu \mathrm{m}^{2}\right.$, Z-scale: $\left.30 \mathrm{~nm}\right)$. (E) Profiles corresponding to the cross-section line shown in images A (1,2 are E.1 and E.2, respectively) and B (3 is E.3), and (F) phase image of the marked area in image C. (Reproduced with permission from reference 68, copyright 2011 American Chemical Society).

\subsection{Vesicle Fusion Method Leading to Supported Lipid Bilayers (SLBs)}

Vesicle fusion is an easy and reliable method to form supported lipid bilayers from zwitterionic vesicles on siliceous substrates. High-quality SLBs are produced via a vesicle fusion method that has three stages namely, vesicle adsorption on the substrate followed by vesicle rupture, fusion, and bilayer spreading. Complex SLBs can be created by optimizing the experimental conditions, temperature, buffer selection, and with the use of $\alpha$-helical peptides which enhances the rate of vesicle fusion [70]. A key parameter for SLB formation via vesicle fusion is the deposition temperature as few lipids exist in gel phase at room temperature. Moreover, the outcome of vesicle fusion depends on the solution $\mathrm{pH}$, ionic strength, presence of divalent cations, nature of lipids and the substrate over which the fusion takes place [71]. Successful vesicle fusion depends on the high-quality vesicle preparation, and the method works with a narrow range of supports and lipid composition. Industrially useful surfaces such as gold and titanium oxide vesicles typically adsorb but tend to remain intact. However, vesicle fusion can lead to SLB formation on smooth, single-crystal gold surfaces while titanium oxide surfaces demands additional steps of wet treatment and thermal annealing [72]. Studies have been done to see the effect of geometric structure of lipids on vesicle fusion. Intrinsic curvature of a vesicle's component lipids is the deciding parameter in the events that occur after the vesicle interacts with the substrate. It was seen that lipid shape will determine the stability and feasibility of the transient substructures that further leads to SLB formation [73]. Rupture of vesicles and the formation of SLBs are dependent on a molecular-level interaction between lipids and the solid supports. The combination of QCM-D and AFM have recently allowed the researchers to characterize the intermediate states leading to SLB formation [22]. Recently a methodology was explored wherein "native membrane vesicles" (NMVs) were merged with "synthetic" vesicles containing PEGylated lipids that promoted SLB formation. These hybrid vesicles resulted in the spontaneous formation of SLBs while maintaining transmembrane protein mobility and activity. This top-down approach provided an insight into how biomimetic surfaces derived from native membranes [74].

Unilamellar vesicle preparation along with quality control are two essential requirements that involve technical skill and resources and are needed to achieve a planar lipid bilayer via vesicle fusion. Furthermore, vesicle rupture occurs on a limited set of substrates and this necessitates the need for an alternative method. Recently, the process of solvent-assisted lipid bilayer (SALB) formation on silicon dioxide and gold has been explored [75]. This alternative technique to form supported lipid bilayers 
does not require the preparation of vesicles. The ternary system is created involving an aqueous buffer, mixture of lipids, and water-miscible alcohol is made to come in contact with the solid support through a fluidic chamber. Phase transition occurs in the bulk itself by increasing the water content and subsequently forming vesicles [76].

\subsection{Self-Spreading of Lipid Layers on Solid Surfaces}

Among several methods discussed so far for the fabrication of SLB, a self-spreading technique whereby lipid molecules self-assemble at a solid-liquid interface which is of immense advantage for applying novel devices such as molecular separation and molecular gate devices. The self-spreading is driven by hydrophilic-hydrophilic interaction between the solid support and the lipid bilayer [77]. For studying the self-assembly of phospholipid membranes on mica, ellipsometry has been used. The advantage of using this technique comes from its real-time monitoring surface mass, thickness, and refractive index along with adsorption and transition kinetics of the membrane [78]. A variety of surfaces have been used in the past such as $\mathrm{Pt}, \mathrm{Au}, \mathrm{Ag}, \mathrm{Al}_{2} \mathrm{O}_{3}$, and alkyl derivatives such as alcohols, amines, and thiols for the assembly of an organized system [79]. The interactions between the oxide support and planar bilayers and the kinetics of membrane spreading are due to the subtle balance among various forces acting between them such as van der Waals, electrostatic, hydration, and steric interactions. Membrane spreading over planar glass support was found to be favorable at low $\mathrm{pH}$ regardless of the net charge on the bilayer [80]. A study has confirmed that lipid bilayers can be fabricated on a porous material by the mechanism of self-spreading which was further validated using fluorescence and AFM studies [81]. Hydrophilic surfaces act as the main stage for self-spreading and, therefore, the position and the direction of self-spreading can be modified using hydrophobic patterns on a hydrophilic surface. Following a similar route, a study has been undertaken to investigate the self-spreading of SLB on nanostructured silicon surface with comparable dimensions to the thickness of the layer [82]. The common fabrication methods to generate biomimetic lipid membranes are listed in Table 1, along with some comments on the advantages and disadvantages of each.

Table 1. Summary of selected artificial lipid membrane fabrication techniques and some of the advantages and disadvantages associated with each technique.

\begin{tabular}{|c|c|c|c|c|}
\hline $\begin{array}{c}\text { Artificial Lipid } \\
\text { Membrane Model }\end{array}$ & Advantages & Disadvantages & Applications & References \\
\hline Vesicle fusion & $\begin{array}{l}\text { Planar bilayer that fully coats the } \\
\text { solid support }\end{array}$ & $\begin{array}{l}\text { Bilayer formation on limited set of } \\
\text { hydrophilic substrates - } \\
\text { borosilicate glass, mica, } \\
\text { silicon dioxide }\end{array}$ & Biosensors, drug delivery & [75] \\
\hline $\begin{array}{l}\text { Monolayers at } \\
\text { air-water interface }\end{array}$ & $\begin{array}{l}\text { Achieving well-controlled surface } \\
\text { morphologies, controlled } \\
\text { composition, adjustable physical } \\
\text { state, stability. }\end{array}$ & $\begin{array}{l}\text { Protein unfolding is observed at } \\
\text { the interface, single layer. }\end{array}$ & - & {$[83,84]$} \\
\hline $\begin{array}{l}\text { Langmuir-Blodgett } \\
\text { type approaches }\end{array}$ & $\begin{array}{l}\text { LB parameters (transfer pressure } \\
\text { and mode) can modify the film's } \\
\text { characteristics, ultrathin films of } \\
\text { well-controlled composition can } \\
\text { be formed }\end{array}$ & $\begin{array}{l}\text { Requirement to measure the } \\
\text { surface pressures of monolayers, } \\
\text { need of water-immiscible } \\
\text { spreading solvent, requires } \\
\text { successful transfer to substrate }\end{array}$ & $\begin{array}{l}\text { Molecular electronics, } \\
\text { non-linear optics, conducting } \\
\text { thin films, biosensors }\end{array}$ & [85-87] \\
\hline $\begin{array}{l}\text { Supported lipid } \\
\text { monolayers }\end{array}$ & $\begin{array}{l}\text { Ease of preparation, stability, } \\
\text { patterning, surface sensitive } \\
\text { techniques can be applied as the } \\
\text { support stabilizes the membrane, } \\
\text { platform to probe receptor } \\
\text { signaling events }\end{array}$ & $\begin{array}{l}\text { Incorporation of trans-membrane } \\
\text { proteins leads to loss of lateral } \\
\text { mobility and function }\end{array}$ & $\begin{array}{l}\text { Excellent platform for sensor } \\
\text { and array technologies such as } \\
\text { heterogeneous analytical assays } \\
\text { for environmental monitoring, } \\
\text { drug discovery, and drug testing }\end{array}$ & {$[56,88]$} \\
\hline $\begin{array}{l}\text { Self-assembled } \\
\text { monolayers }\end{array}$ & $\begin{array}{l}\text { Control over ligand density, } \\
\text { homogeneity and orientation, } \\
\text { simplicity of formation process }\end{array}$ & $\begin{array}{l}\text { Lacks lateral mobility, an } \\
\text { important aspect of } \\
\text { cellular membranes }\end{array}$ & $\begin{array}{l}\text { Interaction studies can be } \\
\text { done easily }\end{array}$ & [89] \\
\hline $\begin{array}{l}\text { Tethered-lipid } \\
\text { membranes }\end{array}$ & $\begin{array}{l}\text { Formed on a variety of substrates, } \\
\text { high electrical sealing properties } \\
\text { and High stability, incorporation } \\
\text { of proteins }\end{array}$ & Reduced lipid mobility & $\begin{array}{l}\text { Biotechnology } \\
\text { applications with membrane } \\
\text { proteins, particularly biosensing }\end{array}$ & {$[88,90]$} \\
\hline
\end{tabular}




\section{Lipopolysaccharides in Monolayer Systems}

Most of the signaling pathways on the cell membrane are contact-dependent and initiated when a ligand binds to a receptor. The response is regulated by the biophysical properties of interaction, bond lifetimes, receptor spatial organization and mechanics at the interface. A supported lipid bilayer is such a model where the mechanics can be manipulated to measure signaling outcomes. In addition, SLBs offer experimental advantages for planar samples to be characterized by surface-sensitive techniques, the ability to precisely pattern fluids, and incorporate properly oriented transmembrane proteins [91]. Supported lipid bilayers have proven effective as model membranes with lateral lipid mobility for investigating biophysical processes thus expanding our toolkit for functional membrane design, with potential applications for biosensing. Lipopolysaccharide (LPS) is an important human endotoxin causing membrane disruption [92]. The primary bacterial trigger of inflammation is LPS which interacts with the receptors present in the membrane. The review focuses now on LPS monolayers wherein the structure-function relationship responsible for the endotoxic activity can be understood. The study of the fabrication of LPS monolayers will also give some idea about the mechanistic details of the drugs that can block the LPS-induced inflammation in a serious medical condition known as sepsis that is a serious problem in hospitals worldwide [93].

\subsection{Lipopolysaccharide Structure}

Lipopolysaccharides, also referred to as endotoxins and lipoglycans are large molecules consisting of a lipid A, core oligosaccharide (inner and outer core oligosaccharide joined by a covalent bond) and polysaccharide composed of O-antigen also referred to as the O-side chain. LPS are found in the outer membrane of Gram-negative bacteria as a major component and are very important for maintaining the structural integrity of the membrane. Lipid A is a major component, and, under normal circumstances, it consists of (1-6) linked phosphorylated glucosamine disaccharide connected with multiple fatty acids (generally 4 to 7 hydrocarbon chains) anchoring them into the hydrophobic region of the outer leaflet of the bacterial cell membrane [94]. The core oligosaccharide component is directly attached to Lipid A and is generally composed of sugars such as heptose, 3-deoxy-D-manno-oct-2-ulosonic acid, also known as Kdo (keto-deoxy-octanoate), hexose, and hexosamine. The inner core generally consists of 2-keto-3-deoxyoctonoic acid (also Kdo) and L-glycero-D-manno heptose sugar (Hep) and the outer core consists of mostly hexoses and hexosamines [95]. In many cases, the core contains other components such as phosphates, amino acids, and ethanolamine substituents, often attached to the sugar. O-antigen is attached to the core oligosaccharide comprising the outermost domain of LPS. Generally, the O-side chain and the core together constitute a hydrophilic part of LPS that is responsible for surrounding the bacteria in the aqueous medium. The presence or absence of the $\mathrm{O}$-antigen moieties refer to the capped and uncapped LPS, respectively. The LPS molecules are also classified as rough and smooth, depending upon the absence or presence of the O-side chains, respectively [96-99]. The role of LPS in the bacterial membrane is to stabilize its structural integrity, and hence make it resistant to a variety of antimicrobial agents. Since the LPS is responsible for the release of inflammatory cytokines, it can mobilize the immune responses in a large area around the site of infection causing septic shock, and in some cases, even death. Therefore, a detailed study of the structure and interactions of LPS is necessary. The complex composition along with the structural information of LPS is shown in Figure 5 [95].

The study of the properties of LPS was carried out in the mid-20th century. The effects of physical and chemical properties and the antibiotics on the biological properties of purified LPS have been investigated $[100,101]$. LPS and the assembly of it in the form of monolayers has been given importance since the 1950s as shown in Figure 6. Some monolayer experiments on LPS can be observed around the 1960s [102]. In the late 1960s, studies of isolated LPS had suggested a bilayer structure of LPS formed by the hydrophobic bonding between two monolayers of polysaccharide and associated lipid [103]. Some later works can be seen indicating the formation of a mixed monolayer of LPS and phospholipid [104]. LPS monolayer studies started significantly in the 1990s. 


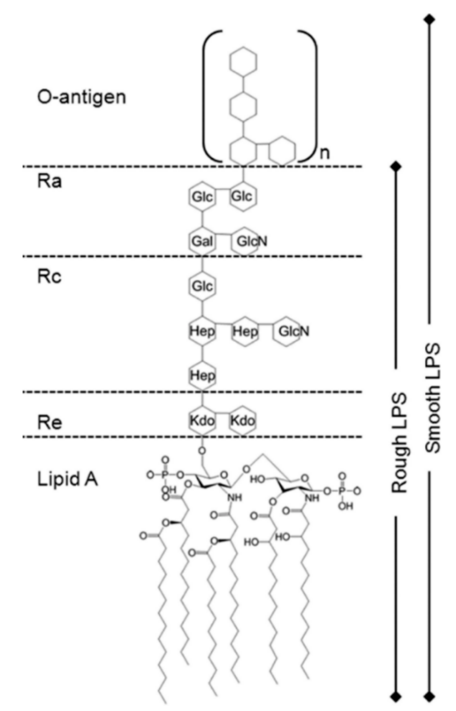

Figure 5. Schematic of the organization of Escherichia coli lipopolysaccharide (LPS). LPS was from the rough mutant J5 strain of E. coli O111:B4, which produces a Rc chemotype with a core oligosaccharide as described by Müller-Loennies et al. The original R mutants, which defined the different chemotypes were from Salmonella minnesota, so in this paper we use the terms $\mathrm{Ra} / \mathrm{Rc}$ to denote the chemotype of $E$. coli LPS used according to this convention. Kdo, 2-keto-3-deoxyoctonic acid; Hep, 1-glycero-D-manno heptose; Glc, glucose; Gal, galactose; GlcN, glucosamine. The Lipid A tails consists of four (R)-3-hydroxy-mystic acids, one myristic acid, and one lauric acid. Additional phosphates and ethanolamines on Kdo and Hep have been omitted for clarity. (Reproduced with permission from [95], copyright 2013 American Chemical Society).

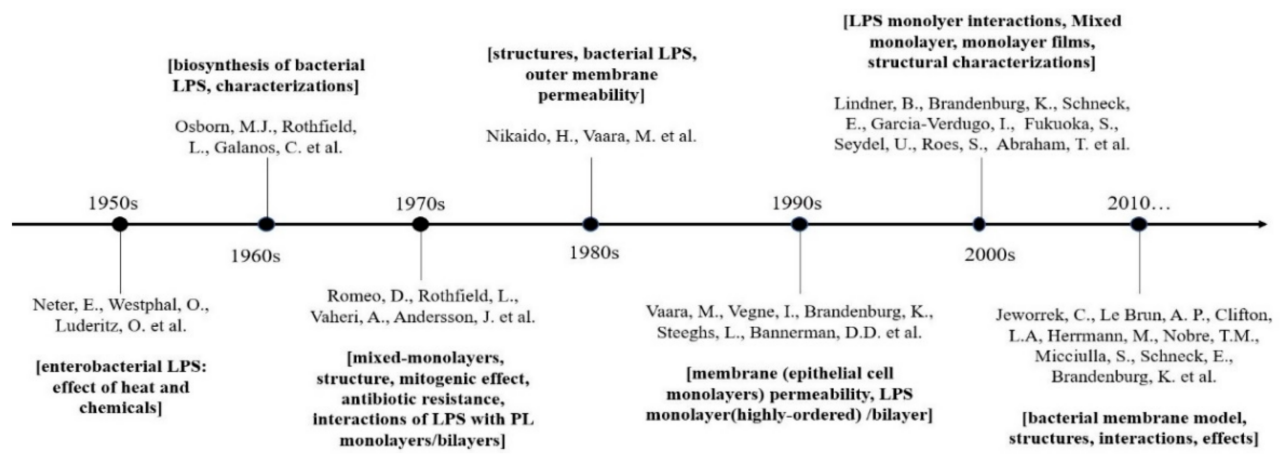

Figure 6. Timeline showing the events for studying LPS and its monolayers.

\subsection{Formation Conditions of Lipopolysaccharide (LPS) Monolayers}

The formation of LPS monolayers has been performed under different conditions. A variability of choices in the subphase composition, choice of spreading solvents, and the amount of LPS deposited can be observed in the reported literature. For the monolayer experiment of LPS at the air-water interface, almost all the monolayers are formed using the Langmuir trough. The selection of appropriate solvent and subphase along with the concentrations of the different solutions are crucially important for the formation of the LPS monolayer. The volatile solvents are left to evaporate after spreading on the surface of the subphase before performing any other tasks. In research performed with R595 LPS, the LPS was dissolved in 10:1 chloroform/methanol mixture at a concentration of $1 \mathrm{mM}$ and was carefully dropped onto the subphase of deionized water containing $5 \mathrm{mM}$ HEPES buffer at $\mathrm{pH} 7.0$ to form a monolayer of LPS at the air-water interface [105]. 9:1 ratio of chloroform/methanol mixture by volume has also been used for dissolving the LPS [94]. The LPS monolayers were also found to be prepared by making a bulk solution of LPS $(1.0 \mathrm{mg} / \mathrm{mL})$ in the solvent: liquid phenol ( 9 parts phenol/1 
part water) mixed with chloroform and petroleum ether (2:5:8 by volume respectively) and, spreading the LPS solution on the aqueous subphase (purified water, $18 \mathrm{M} \Omega$ resistivity) [99]. A study reported the formation of LPS-monolayer using the mixture of chloroform and methanol in the ratio of 2:1 as a solvent and HEPES buffer as a subphase. The LPS was first solubilized in 2:1 chloroform/methanol mixture at a concentration of $0.5 \mathrm{~g} \cdot \mathrm{L}^{-1}$. After a thorough cleaning, the Teflon trough was filled with $8 \mathrm{~mL}$ HEPES buffer ( $\mathrm{pH}$ 7.0). The LPS solution was then spread with a high-precision microsyringe at the clean air-water interface to form a monolayer [106]. Another study has used Rc LPS and the liquid subphase of $20 \mathrm{mM}$ sodium phosphate ( $\mathrm{pH}$ 7.0). The solution of Rc LPS was made with the solvent mixture of chloroform, methanol, and water in the ratio of 6:4:1 by volume respectively [95]. The LPS monolayers are also found to be formed by depositing an LPS suspension in $60 \%$ chloroform, $39 \%$ methanol and 1\% water (v/v) onto a cleaned air-liquid interface of $20 \mathrm{mM} \mathrm{HEPES} \mathrm{buffer} \mathrm{with} \mathrm{pH}$ 7.2, containing some salts [107]. The preparation conditions for these LPS monolayers are summarized in Table 2, along with the key observations concerning the monolayer behavior. It is important to note that spreading from single pure solvents, as is possible for many more commonly studied lipids, is not possible for LPS due to solubility limitations and careful attention must be paid to choosing an appropriate mixed solvent system. Information about the compressibility of the monolayer and the presence of features suggesting structural transitions can be inferred from the isotherm and have been found to differ depending on the source of LPS in ways that warrant further study. Studies of LPS monolayers at the air-water interface have some advantages in terms of control of composition and physical state, which are more challenging for the supported bilayer systems.

Table 2. Conditions used for the preparation of LPS monolayers at the air-water interface and key isotherm characteristics.

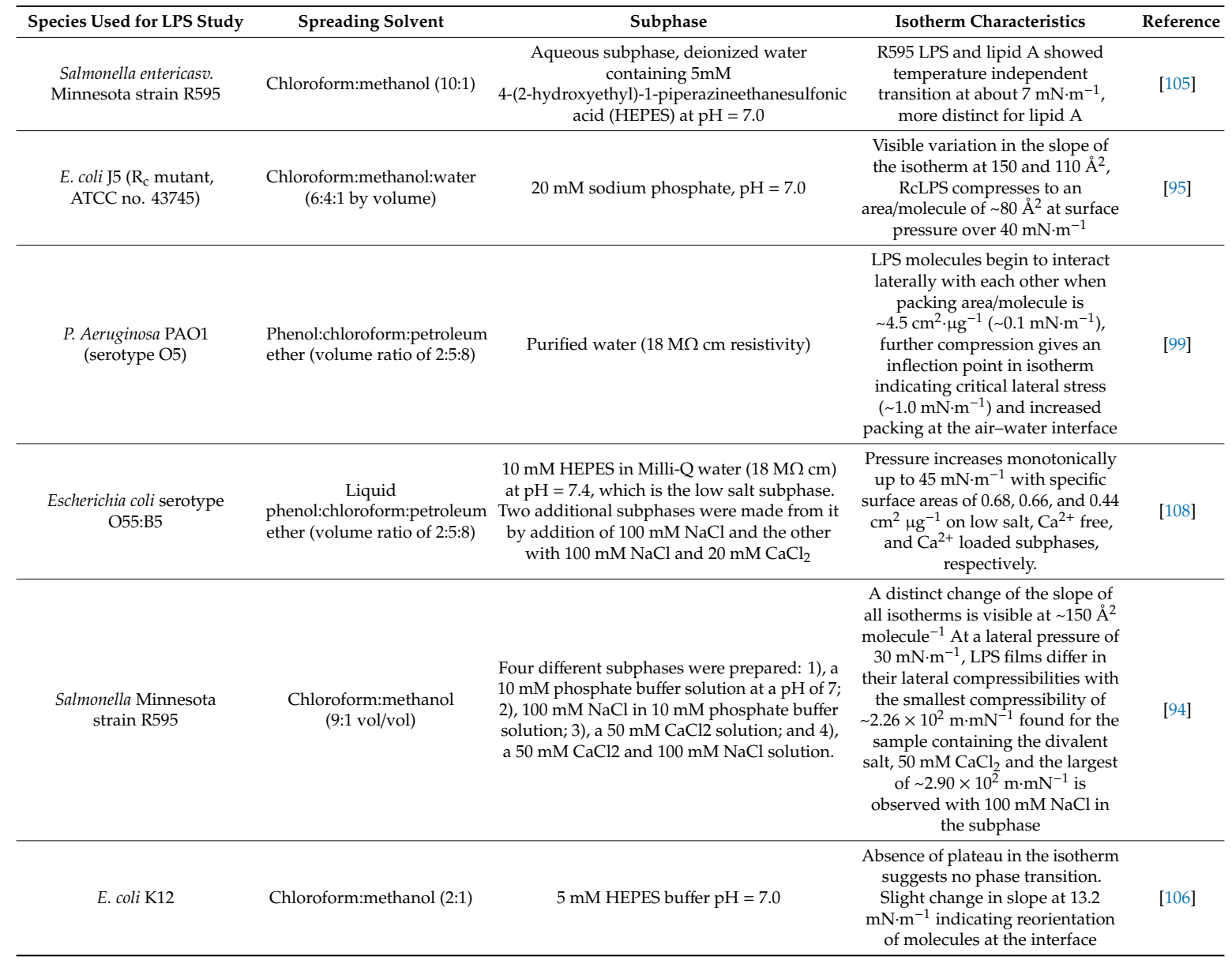




\subsection{Structure of LPS Monolayers}

The detailed knowledge of the structure of LPS monolayer helps to understand properties of LPS in membranes which is very important to study the interaction between these membranes and antimicrobial agents and for new drug discovery. Generally, most of the cell membranes do not have a secondary membrane but Gram-negative bacteria possess a unique secondary membrane, the outer membrane, which is an asymmetric bilayer made of a phospholipid inner leaflet and a glycolipid outer leaflet. LPS is the main constituent of the outer glycolipid leaflet and hence the main target of membrane-active agents. Lipids, glycolipids, proteins, and glycoproteins are the main components of a biological membrane. The phase separation and domain formation are supposed to have substantial importance in the structural and functional specialization of a complex natural system. The phase separations are responsible for the domain formation in lipid membranes, for instance, liquid-expanded (LE) and liquid-condensed (LC) phases. Most of these domains are cholesterol-rich and referred to as rafts. The studies of the proteins of specific signal transduction pathways that are combined in domains forming signaling complexes are going on. Also, the changes in the domain structures due to the applications of external molecules and the intercalation of proteins have been investigated [105]. Many studies have been used to investigate the LPS monolayers, using a plethora of tools and techniques.

\section{- $\quad$ Lipid A}

Lipid A is the main structural component of the LPS molecule that is responsible for several activities related to endotoxins stimulating the innate immune system. Lipid A shows structural diversity depending upon the different bacterial species regarding the variations of acyl chains they possess. The acyl chains may differ in number, chain length, and functional groups attached to them [109]. One of the most important part of the LPS, lipid A, has been investigated using several monolayer experiments in air-water interfaces. Lipid A is the membrane-forming component of LPS containing the hydrophilic disaccharide backbone with fatty acid chains bound to it. Monolayer isotherms performed for monophosphoryl penta-, hexa-, and heptaacyl and bisphosphoryl hexa- to heptaacyl lipid A have been used to analyze the structure of the lipid A monolayer [110]. Amphiphiles like phospholipids and fatty acids display two kinds of liquid states of the films namely liquid-expanded state (LE) and the liquid-condensed state (LC) which upon compression leads to molecular reorientation to form a compact film [111]. Analyzing the П-A isotherms, all the aforementioned lipid A species show a clear phase transition from liquid expanded (LE) to liquid condensed(LC) state about a similar pressure range, but monophosphoryl heptaacyl, which shows up in a quite lower surface pressure which would correspond to the highest phase transition temperature for a bilayer system. A high-grade purity and homogeneity of the lipid A compounds can be estimated from these distinct phase transitions from LE to LC phases. At a fixed lateral pressure $\left(30 \mathrm{mN} \cdot \mathrm{m}^{-1}\right)$, the molecular space requirements are different for different monophosphoryl lipid A components here showing the highest value for heptaacyl and lowest for pentaacyl component. Among bisphosphoryl lipid A, heptaacyl seems to have higher molecular space requirements as compared to hexaacyl. The results show the linearity in the sequence of molecular space requirement of the monophosphoryl compounds whereas non-linearity is seen for bisphosphoryl hexa- to the heptaacyl lipid A. This suggests no ordered molecular conformation can be expected in the monolayers of monophosphoryl compounds. In contrast, the monolayer formed by bisphosphoryl compounds may show changes in the molecular conformation, indicating the possibility of more conical shape [110]. A conformational concept of endotoxic activity deals with those lipid A structures which have conical molecular shapes leading to disturbance at the site of transmembrane signaling protein. Another study performed by Roes et al. at the subphase temperature of $20^{\circ} \mathrm{C}$ showed a distinct phase transition for lipid A from R595 LPS. The tilt angle between the acyl chains and the diglucosamine backbone in lipid $\mathrm{A}$ is known to be about $47^{\circ}$ which is more than that for R595 LPS (about $33^{\circ}$ ) [105], [112]. Comparatively, a more distinct structural transition is observed for lipid A than R595 LPS. Hence, researchers proposed that the phase transition is more significant for 
the glycolipids with a higher tilt angle because it may allow the denser packing of monolayers while undergoing the reorientation of the lipid molecules. The epifluorescence micrographs of monolayers at the air-water interface with fluorescence-labeled LE domains, which are phase-separated from the LC domains in the coexisting regions, show bright LE domains clearly. However, a quantitative analysis of the domain structures was not possible due to the lower resolution of images. However, the AFM analysis of the monolayers transferred to mica indicates that the height of LE domains of lipid A monolayer was about $1 \mathrm{~nm}$ lower than the LC domains (surrounding monolayers). The size and area of LE domains decrease with an increase in lateral pressure; however, the number of molecules per unit area (considering both LE and LC domains) increases. A decrease in the number of lipid A molecules in LE domains is observed with an increase in the lateral pressure. The more circular geometry of the domains under lower lateral surface pressure seems to become more complex at higher pressure [105]. It can be suggested that the heterogeneous distribution of the acyl chains in the lipid A moiety may contribute to the structural organization of lipid A monolayers.

\section{- $\quad$ Rough LPS}

Several tools and techniques are available to study the monolayer of LPS isolated from different micro-organisms to increase the understanding of its important characteristics. However, information regarding rough LPS is predominant as compared to smooth LPS to explain their interfacial and monolayer properties. Lacking the O-side chains (O-antigen) in rough LPS makes it more convenient to study as compared to heterogeneous O-side chains present in smooth LPS. In general, different types of rough LPS are denoted as $\mathrm{Ra}, \mathrm{Rb}, \mathrm{Rc}, \mathrm{Rd}$, and Re-LPS according to the basal sugar structures they possess, being ReLPS the shortest one [113]. A study of the monolayers of deep rough mutant LPS (R595 LPS: a ReLPS consisting of lipid A plus two Kdo groups) from Salmonella enterica serova Minnesota discussed the topography (particularly phase separation) of the LPS monolayer at the air/water interface of a film balance [105]. The subphase temperature was maintained at $20{ }^{\circ} \mathrm{C}$ and the monolayers were equilibrated at zero pressure for $5 \mathrm{~min}$ to allow evaporation of the solvent. R595 LPS shows a clear phase transition between LE and LC domains around a lateral pressure of $7 \mathrm{mN} \cdot \mathrm{m}^{-1}$ which is comparable to its lipid A moiety. Nearly circular domains of the R595 LPS are like those of lipid A but are smaller. This may be possibly due to the presence of two additional 3-deoxy-D-manno-octulosonic acids and the differences in their fluidity and their gel-to-liquid crystalline phase transition temperature $\left(T_{c}\right)$ values. The AFM height images show about $0.7 \mathrm{~nm}$ of height difference between the LE and LC domains of the LPS which is slightly lower in comparison to lipid A domains. The reason behind this can be assigned to the difference in their tilt angles.

A different study was done by Jeworrek et al. [94] of the deep rough LPS and helped explain the structure and lateral organization of ReLPS monolayers at the air-water interface and its ion-dependent behavior using monovalent $\left(\mathrm{Na}^{+}\right)$and divalent $\left(\mathrm{Ca}^{2+}\right)$ ions. The net charge of -3.6 electrons per molecule of Re LPS was used in this study. According to this study, different modes of LPS-monolayer packing could be explored by changing the ionic strength of the aqueous subphase. Based on their results, $\mathrm{Na}^{+}$ions have unspecific interaction with LPS molecules due to their ability to screen the negative charge of the LPS molecules, whereas $\mathrm{Ca}^{2+}$ ions have specific interaction that cross-links the LPS molecules in the monolayer. The monolayer of LPS is ordered over a large region with high lateral compressibility when $\mathrm{Na}^{+}$ions are present in the subphase at low lateral pressures giving rise to nearly hexagonal packing of hydrocarbon chains. The monolayer becomes more rigid at higher pressures and results in a less perfect, oblique packing with smaller lateral size of highly ordered domains. Moreover, a conformational change in the structure of the headgroup occurs with the increase in the surface pressure leading to the increased thickness of the whole LPS monolayer. Even at lower pressures, the $\mathrm{Ca}^{2+}$ ions in the subphase can increase the rigidity of the LPS monolayer to form an oblique packing of hydrocarbon chains of LPS leading to lower compressibility as compared to the LPS monolayer on a subphase with $\mathrm{Na}^{+}$ions. In the case of $\mathrm{Ca}^{2+}$ ions, there is only a trivial effect on the conformation of the LPS molecules with an increase in the lateral pressure. The intermolecular interactions of $\mathrm{Ca}^{2+}$ ions with lipid phosphates and sugar carboxylates lead to an upright orientation of the sugar moieties 
and cross-linking of the LPS molecules giving rise to only a minor conformational and orientational change with increasing lateral surface pressure. However, a significant decrease in the lateral size of the ordered domains in the monolayer can be observed due to increased packing stress at higher film pressures. Taking both the ions in the subphase, the screening effect of $\mathrm{Na}^{+}$ions are predominant at lower pressures; however, at higher film pressures, the structure and lateral organization of the LPS monolayer are more dependent on the effect of $\mathrm{Ca}^{2+}$ ions. Hence, at an increased film pressure of the magnitude suitable for the biological membrane, the unspecific charge screening effect of $\mathrm{Na}^{+}$ions on the conformations of sugar molecules of LPS tends to be less dominant as compared to $\mathrm{Ca}^{2+}$ ions. Thus, the divalent cations in the inner core region of LPS play an important role in maintaining the outer-leaflet integrity stabilizing the membrane against hydrophobic antimicrobial agents significantly [107].

Another type of rough LPS, RcLPS extracted from a rough strain of E. coli containing lipid A with the first seven sugars of the core polysaccharide was investigated by Le Brun et al. [95]. The lateral structural organization of RcLPS monolayers was studied by grazing incident $\mathrm{X}$-ray diffraction and Brewster angle microscopy whereas the characterizations of the upright structure was done using reflectometry. The pressure-area isotherm of the monolayer of RcLPS shows only a weak phase transition from LE to LC states. The multiple compressions and relaxations of the monolayer showed a slight deviation from the previous $\Pi$-A isotherms indicating that a small amount of RcLPS is going to the bulk of the liquid subphase. This may indicate that the monolayers do not completely collapse into bilayer or multilayer structures at high pressure but that a slow loss of the substances to the subphase occurs, lowering the molecular area in the repeated isotherms at higher pressures. With the help of neutron reflectometry, the vertical structure of the RcLPS at pressures of $20 \mathrm{mN} \cdot \mathrm{m}^{-1}$ and above are resolved as three discrete layers that account for the alkyl tails, an inner head-group, and an outer head-group of polysaccharide with increasing hydration from tails to outer headgroups. The thickness of the hydrocarbon tails, the inner head-group, and the outer head-group were found to be about 12,14, and $15 \AA$ respectively, leading to a $\sim 41 \AA$ thick monolayer of RcLPS. The synchrotron X-ray reflectivity and GIXD show the thickening of the monolayer with increasing lateral pressure due to the increased ordering of the molecules, specifically, more perpendicular to the surface. The lateral structural characterization of the hydrocarbon chains in RcLPS monolayers shows an oblique hexagonal packing at all surface pressures, with only the change in chain tilt angle, which is contrary to the lipid A structure having hexagonal or distorted hexagonal packing at or above the pressures $20 \mathrm{mN} / \mathrm{m}$ demonstrating the influence of polysaccharide chains on the organization of the alkyl chains. The information observed from grazing incidence X-ray diffraction (GIXD) measurements showed a difference in packing behavior for RaLPS monolayer from that observed for lipid A (having no core region) and Re LPS and Rc LPS (with shorter core regions) [107]. For these monolayers, a distorted hexagonal packing was observed near $30 \mathrm{mN} \cdot \mathrm{m}^{-1}$ whereas the Ra LPS monolayers seemed to have ordered hexagonal packing of acyl chains. Moreover, the presence of $\mathrm{Ca}^{2+}$ ions were found to increase the thickness of the monolayer slightly as compared to the monolayer without it. The $\mathrm{Ca}^{2+}$ ions present in the subphase are consistent with the ordered hexagonal packing of the Ra LPS monolayer while the presence of ethylenediaminetetraacetic acid (EDTA) in the subphase has been found to make a less ordered packing affecting the structure of the core region.

\section{- $\quad$ Smooth LPS (Native/Wild-Type LPS)}

The stable monolayers of smooth LPS having O-side chains (OSC) are found to be reconstituted at the air-water interface in pure water as well as at the air-water interface of water having different ionic species. Abraham et al. have performed Langmuir film balance studies and analyzed the plots of surface pressure versus surface area per unit weight ( $\Pi-\mathrm{A}$ isotherms) for a native LPS extracted from the outer membrane of a Gram-negative bacteria, Pseudomonas aeruginosa to study its structural organizations [99]. The strong lateral interactions of LPS monolayer was observed at higher lateral pressure regions which may be the characteristic lateral pressure of the outer membrane of P. aeruginosa. At higher lateral stresses greater than $30 \mathrm{mN} \cdot \mathrm{m}^{-1}$, representing the biologically relevant membrane 
condition, the value of surface compressive modulus is found to be $\sim 225 \mathrm{mN} \cdot \mathrm{m}^{-1}$ which suggests that the LPS monolayer at the air-water interface is very rigid indicating the confinement of polysaccharide moieties. At lower surface pressures, the addition of salt cations significantly reduced the area per unit weight of LPS indicating the change in the structural organization and conformation, due to the salt-bridging and the alterations in its lateral interactions, showing the clear influence of the ionic environment in the lateral structure of LPS monolayers. Based on the П-A isotherm, the collapse pressures for LPS monolayer are significantly higher $\left(42-52 \mathrm{mN} \cdot \mathrm{m}^{-1}\right)$ which points towards the ability of the relevant bacterial membrane component to sustain high lateral pressures. However, the addition of salts particularly divalent salts, has been able to reduce the rupture pressure of the monolayers suggesting that the divalent salts seem to lessen the ability of the membrane to withstand the highly stressed conditions. This may be because the high concentrations of divalent cations can expedite the transfer of DNA and other proteins across the membrane, probably via openings. The viscoelastic behavior of LPS monolayers was also observed which could protect the bacterial outer membrane from structural failure by providing time for adaptive phenotypic response to prevent detachment from the substrate during colonization of bacterial surfaces.

The structural and conformational investigations of monolayers of wild-type bacterial LPS from E. coli O55: B5 on the air-water interface with aqueous solutions containing different concentrations of monovalent and divalent cations using the Langmuir trough and X-ray and neutron reflectivity (XRR and NR) have been performed by Micciulla et al. [108]. П-A isotherms provide some information regarding contributions of electrostatic and O-side chain (OSC)-induced (polymer-steric) forces on intermolecular interactions and elastic moduli of the LPS monolayers. In agreement with the earlier researches on the rough LPS, the divalent cations seem effective in ion-specific bridging with the negatively charged phosphates and carboxylates present in the LPS moiety, in addition to the generic electrostatic shielding effect. The characterization of the structure of LPS monolayers by complementary $x$-ray reflectivity (XRR) and neutron reflectivity (NR) reveals a bimodal saccharide distribution as expected from the chemical structure of the smooth LPS (S-form LPS): one with a dense and compact layer consisting negatively charged inner oligosaccharides (IOS) and another slightly more dilute and the extended region containing linear polysaccharides termed OSCs. The cations (mainly divalent), affect the denser oligosaccharides (IOSs) and hydrocarbon portions substantially, indirectly affecting the extended region of OSC distribution also, through a change in the molecular area of LPS.

\section{Physical Properties of Supported Lipid Membrane}

The deep complexity of biological membranes lies in their diverse physical-chemical properties such as two-dimensional fluidity, material elasticity, thermal fluctuations, chemical diversity, and rich phase behavior. Due to the inherent attributes of chemical heterogeneity, phase behavior, and dynamics, lipid bilayer membranes can produce a set of time-dependent functions for the biological membrane such as lipid reorganization, protein clustering, signaling, recognition, and transportation [114]. Different techniques have been used so far to evaluate the structure, composition, and properties of lipid membranes. Fluorescence microscopy investigates the domain morphology of layers along with a detailed study of membrane's molecular organization whereas, X-ray reflectivity has the potential to determine a thickness and density profile matched to a slab model. Real-time monitoring of lipid layer formation and binding interaction with molecules has been undertaken using diffraction and neutron reflectivity, Raman, and infrared spectroscopy. AFM has been used to gather surface details in terms of the occurrence of peculiar structures and defects [115]. During the past decade, AFM has resolved various problems in the field of biochemistry and biophysics regarding the characterization of supported lipid films. One of the unique features of this technique is that it can measure surface forces with nanometer lateral resolution. Force measurements are of primary importance as they give a deep insight for understanding the physical and chemical properties of lipid layers and their constituents [55]. Work has been undertaken towards understanding the compressibility of bilayer lipid membranes perpendicular to the membrane plane, as characterized by elasticity modulus. This quantity was 
found to depend on lipid composition and cholesterol content. In addition to this, the ultrasound velocimetry method has been used to study the compressibility of liposomes and temperature scanning densitometry gave information about changes in the specific volume of liposomes. The degree of unsaturation of fatty acids played a crucial role as it was found to affect the structural state of the membrane along with the compressibility [116]. From a theoretical point of view, the precursor lipid film is a consequence of the colloidal interactions between the film and the substrate which is spontaneous if it is energetically favored. Lateral bilayer spreading critically depends on the degree of hydration of the substrate [117].

With the development of stimulated emission depletion (STED) microscopy, a spatial resolution down to $30 \mathrm{~nm}$ has been attained in living cells. Moreover, study of diffusion kinetics of lipids in the membranes on the sub-millisecond scale has been achieved using fluorescence correlation spectroscopy (FCS). Spatial and temporal resolution when combined has been used to observe transient lipid interactions in live-cell membranes. In this approach, a fluorescent lipid analog has been used to study phase separation and lipid diffusion characteristics of the membrane [118]. STED-FCS allows us to obtain such data at one spot at a time. A potential remedy to this problem is the use of scanning STED-FCS (sSTED-FCS) to study the spatiotemporal properties of fluorescent lipid analogs in the plasma membrane. It allows the mapping of membrane dynamics with a scanning trajectory of several micrometers and with a spatial resolution of $60 \mathrm{~nm}$ and temporal resolution of sub millisecond. Through this approach, one can identify the zones where there is hindered diffusion of lipid analogs in the plasma membrane with the highest spatiotemporal resolution [119]. Most of the investigations done so far on lipid bilayers are under aqueous conditions since water molecules keep the biological membranes intact and unified. However, some of the physical and chemical properties of lipid membranes such as compositional overview, electrical investigations at the nanoscale level, and their conductive nature can be understood only under dry conditions. It is known that lipid layers in dry conditions are prone to structural instabilities and, therefore, to prevent this sort of delamination, various techniques have been tried by the scientific community such as the addition of lyoprotectants during the preparation of SLB and freeze-drying strategy [68].

Studies have shown that the substrate has a critical role to play in the physical structures and properties of the supported membranes. Interaction of a lipid membrane with the substrate is an influential factor during vesicle fusion to form SLB, has a crucial influence on the cell membrane's role in signal transduction and molecular recognition as determined by molecular diffusion, domain formation, and reactivity of SLB [120]. It has been seen that changing the underlying substrate has an impact on bilayer fluidity, and lipid and ligand spatial orientation, and clustering of receptors. Substrates can be modified to achieve the rigidity required to study the mechanics of SLB [91]. The LB technique employed to measure the thermodynamic properties of lipids uses a variety of substrates and it has been demonstrated that the quality of transferred monolayer is greatly enhanced by using ultraclean, hydrophilic substrates with low surface roughness giving rise to well-packed, uniform SLBs [56]. In order to see clearly the cell signaling and biosensing with the analyte of interest, it is important to prevent misleading non-specific interactions taking place and, therefore, functionalizable and non-fouling properties of substrates become substantial. The substrate has to be designed in a way to reflect the real mechanical stiffness experienced by the cells in a physiological microenvironment in order to get similar cellular responses in the studies [121].

Even though the basic structure of biological membrane was established 75 years ago, the physical properties of lipid bilayers are still being investigated as further information about the membrane's organization and dynamics is uncovered. Molecular oxygen has been used as a probe due to its small size and appropriate hydrophobicity which allow it to enter the small vacant pockets in the membrane. Bimolecular collision rates between molecular oxygen and nitroxide spin labels in the membrane gave majority of the details [122]. Another versatile and promising tool to measure the physical-chemical properties of supported membranes is the indirect technique of optical imaging ellipsometry (IE). The quantitative characterization of structural and functional thin film properties 
of supported phospholipid membranes was made possible by this method. Four broad classes of membrane-based properties include bilayer thickness and spatial homogeneity, the kinetics of bilayer formation at interfaces, lateral heterogeneity and phase separation, and kinetics and binding affinity with the ligand, are all addressed using IE [123]. Another aspect of biophysical properties of the membrane is the controlled spatial organization of lipids which in turn have an active role in cell function. A recent report highlighted the role of biophysical properties in the membrane's bending and stretching behavior and finally affect cell signaling. It became very well understood from the study that the physical and chemical features have evolved together for cells to function properly [124]. The common techniques used to characterize various properties of supported bilayers are listed in Table 3.

Table 3. Summary of techniques useful for surface supported bilayer characterization.

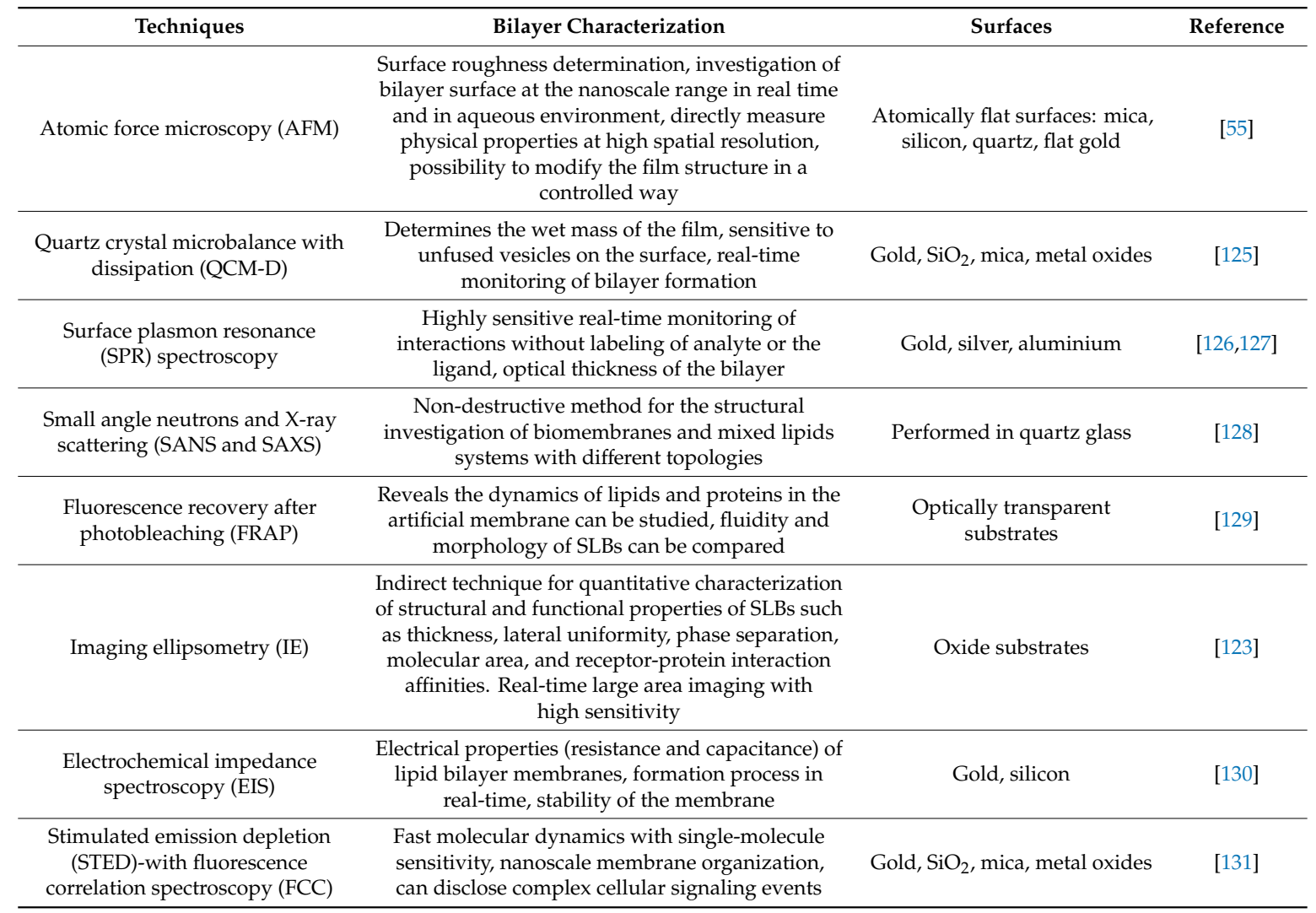

\section{Types of Tethered Bilayer Lipid Membranes (t-BLMs)}

During the past two decades, solid-supported membranes have been thoroughly researched due to their compatibility with wide-ranging surface characterization techniques used to study protein-membrane interactions. Tethered bilayers are one such construction where the proximity issue of the membrane with the support has been solved to remove contact between integral proteins and the solid surface. Several membrane construction strategies have been envisaged. Different constructions and combinations of membrane models separate the bilayer from the surface by intercalating spacer molecules or layers [132]. The reason for the development of tethered membranes is the endeavor to achieve high electrical sealing properties and high stability. Tethering can be achieved using a lipid-like molecule functionalized with a spacer segment that remain suspended from the solid support. Alternatively, protein tethers can be used to attach a membrane to its support [90]. Different approaches to attach the artificial membrane with the solid support are reported including the one employing DNA tethers for tethering planar lipid bilayers as membrane patches to either a supported lipid bilayer or on a DNA functionalized surface as seen in Figure 7. In both cases, giant unilamellar vesicles (GUVs) 
displaying antisense DNA on a DNA-lipid conjugate are first tethered on to the substrate of interest. Tethered GUVs were found to flatten as more DNA hybrids were formed [133]. All tethered bilayer lipid membranes ( $t$-BLMs) reported to date use tethers composed of dual domains, a lipophilic portion to insert into one of the leaflets of the lipid membrane, and a hydrophilic domain that helps in attaching the tethering molecule to the support [134].
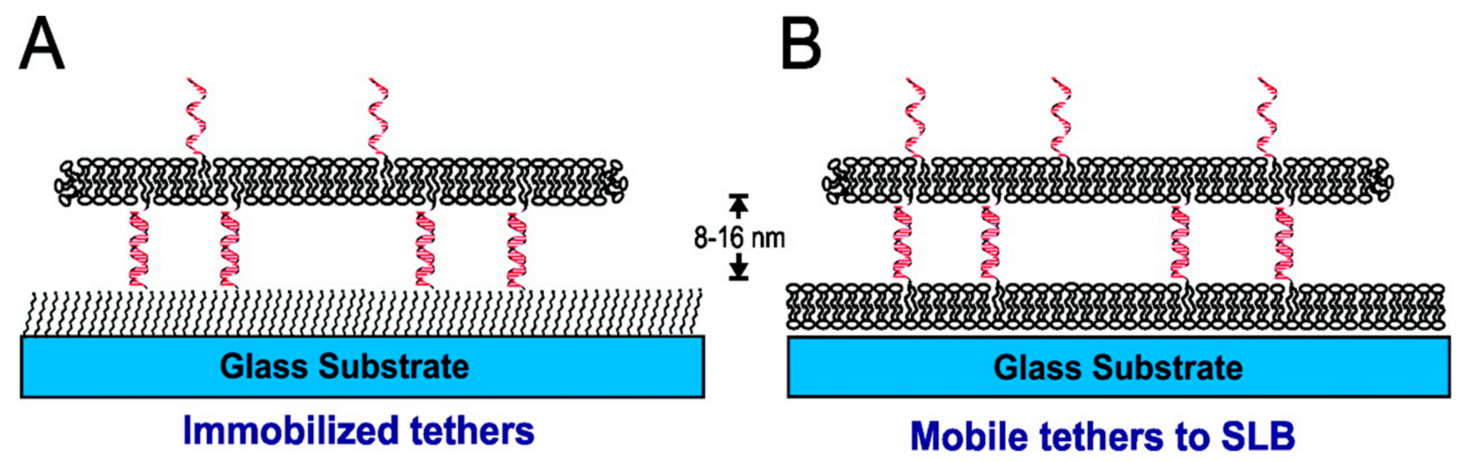

Figure 7. Schematic diagram of DNA-tethered lipid bilayer patches formed by rupture of giant unilamellar vesicles on two different substrates. In part A, the tethering DNA is covalently attached to the substrate and so the DNA tethers are not mobile (the lateral density can be controlled; the remainder of the surface is passivated with phosphate groups). In part $\mathbf{B}$, the tethering DNA is displayed on the surface of a supported lipid bilayer, so the DNA tethers are laterally mobile. This design brings two fluid bilayers into proximity defined by the length of the DNA tether ( $\sim \mathrm{nm}$ for a 24 mer hybrid; $\sim 16 \mathrm{~nm}$ for a 48-mer hybrid). (Reproduced with permission from [133], copyright 2011 American Chemical Society).

With the rapidly growing interest in tethered bilayers, a whole spectrum of different anchor compounds was developed. Attempts were made to utilize the concept of vesicle fusion with multilamellar vesicle compositions (MVC) for creating t-BLMs using sparsely anchored self-assembled monolayer (SAM) comprising of $0.05 \mathrm{mM}$ (total disulfide concentration) of [HC18] $\mathrm{S}_{2}$ and 2-hydroxyethyl disulfide [the disulfide of $\beta$-mercaptoethanol, $(\beta \mathrm{ME}) \mathrm{S}_{2}$ ] of various molar ratios. [HC18] $\mathrm{S}_{2}$ is the disulfide form of the molecular anchor. The study also justified that MVCs fused quickly to the anchor layer and formed tethered bilayers with low residual defects [135].

Membrane systems with lipid rafts are considered essential for signal transduction, cell adhesion, and protein sorting. The tethered bilayer lipid membrane is a promising candidate for mimicking natural biological membrane showcasing lipid rafts. Work has been done to fabricate a nanoarray of tethered lipid bilayer raft membranes (t-LBRMs) by using thermal assisted ultraviolet nanoimprint lithography (UV-NIL). Nanopatterns of UV-curable poly (vinyl alcohol) (PVA) hydrogels crosslinked with a polymer network were used over the gold substrate for direct vesicle fusion and a mixed SAM-assisted vesicle fusion method. This platform has potential applications in terms of developing nanochips or nanodevices [136].

A study has been undertaken to gather information regarding the ionic conductance and selectivity in tethered bilayer membranes using electrical impedance spectroscopy indicating the variation of ionic conductance with different chemical structures of reservoir tethers. A simple network model was used to justify that reservoir behavior is the dominant factor as compared to the channel density in the tethered membranes, controlling the overall conduction in a t-BLM [137]. Work has been done on engineered membrane-bound ion channels based on supported tethered bilayers. Two ion channels studied include one with the highly conducting $\mathrm{Ca}^{2+}$ activated $\mathrm{K}^{+}$channel and the other being a synthetic one based on the channel-lining domain of the nicotinic acetylcholine receptor. Such a system can serve as a model for studying ion permeation, gating kinetics, and pharmacology [138].

For obtaining nano-structural information on lipid systems, neutron reflectometry (NR) is considered very useful. Structural details of the polar head and tail region such as their thicknesses 
and their dependence on the lipid bilayer's phase can be obtained via this technique. NR has been used often to give a high-resolution structural characterization of different t-BLM architectures such as providing details of the structure formed by co-adsorption of varying ratios of lipid and short-chain spacer molecules. The information obtained following this line is useful for predicting optimal conditions for protein insertion into the tethered bilayer system [139].

A great challenge lies in unlocking the secrets of biological membranes. The growing interest in designing lipid membranes on solid surfaces and in an attempt of removing the drawbacks of earlier models gave us t-BLMs which helped to reconstitute complex mechanisms in membrane models. Tethered membranes are the most attractive approach to develop a biomimetic system with improved stability of membrane proteins and applicability in sensing of pharmacologically membrane-active compounds opening potential benefits in diagnostic test systems [140]. Replacement, refinement, and reduction are the 3Rs strategy proposed by Russell and Burch for limiting animal use and using $\mathrm{t}$-BLMs as an alternative method for studying structural and functional aspects in the biological system. Effects and interactions of lipid membrane-targeting compounds have been studied such as the interaction of amyloid $\beta$-proteins with membrane lipids to detect the early stages in Alzheimer's disease [141]. To meet the requirements of fundamental and applied sciences, the tethered bilayer platform is the most appropriate. More effort has been done in designing quicker and cost-effective methods to produce tethered lipid bilayers for an increasingly wide range of biotechnology applications that enable nanoliter sample volumes and robotic spotting to resemble a molecular toolkit for sensitive detection [142]. Table 4 give a listing of the common anchoring groups used to create tethered lipid bilayers.

Table 4. Types of anchoring groups for creating tethered lipid bilayers.

\begin{tabular}{ccc}
\hline Anchoring Groups/Spacer Unit & Advantages & Reference \\
\hline DNA & $\begin{array}{c}\text { Flexible, facilitates docking, allows spacing between } \\
\text { vesicles after docking to probe the effect of distance } \\
\text { on fusion of vesicles }\end{array}$ & {$[143]$} \\
Thiols & $\begin{array}{c}\text { Increase membrane hydration and ion transport } \\
\text { without reducing bilayer impedance, enable } \\
\text { functional incorporation of membrane proteins }\end{array}$ & {$[144]$} \\
\hline His-tagged Protein & Imparts intramolecular flexibility & {$[134]$} \\
\hline Polymer & $\begin{array}{c}\text { Successfully incorporate a range of proteins in a } \\
\text { functional form, minimizes negative substrate effects } \\
\text { such as, defect formation, and decreased } \\
\text { lateral mobility }\end{array}$ & {$[145]$} \\
\hline
\end{tabular}

\section{Biological Binding of SLB with LPS}

Biophysical interactions are critical to understanding the role of membrane lipids in the pharmacokinetic properties of drugs and various biologically active molecules. Molecules interact with the membrane in three different ways which include interaction with the lipid headgroups, hydrophobic alkyl chains, and with both the head-group and chain portion of a lipid. Physical characteristics of the molecules such as hydrophobicity, hydrophilicity, and surface charge can significantly influence the interactions with the model membrane as well as their pharmacokinetic properties such as transport, biodistribution, accumulation, and efficacy [146]. Interaction with the lipid membrane is very well established for electroactive compounds such as quercetin, bioactive flavonoid, and epinephrine. During the interaction, the biomolecules adsorb onto the lipid membrane and a conformational change is induced which ultimately leads to binding with its receptor [147]. Anesthetics are among the first drugs studied and characterized for their interaction with biomimetic membranes. The mechanism of action on lipid membranes is different for a different molecule. Some interact by causing local interdigitation of bilayers while others affect the molecular packing of 
constituents in the membrane [148]. When proteins interact with the lipids in the membrane, they can moderate the lipid fluidity which can be observed using X-ray reflectivity along with simultaneous fluorescence microscopy as seen in Figure 8. In return, lipid mobility may influence the fate of the protein for further complex formation. Other studies have shown that surface layer proteins with the ability to self-assemble into crystalline arrays can disturb the arrangement of lipid headgroups via the mechanism of intercalation [149]. Gram-negative bacteria have an asymmetric outer membrane with the inner and the outer leaflets rich in phospholipids and LPS, respectively.

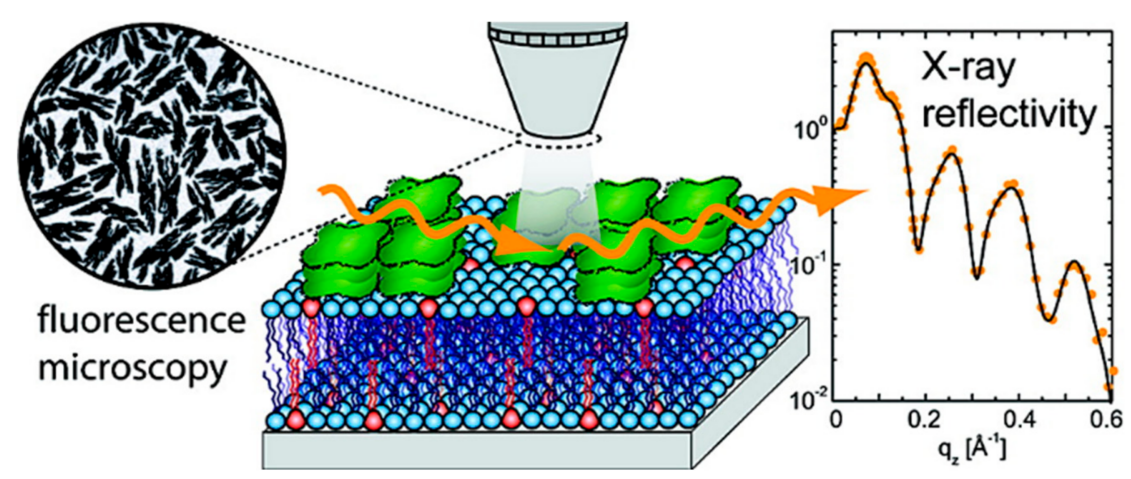

Figure 8. Schematic representation of supported lipid bilayer with proteins at the surface. X-ray reflectivity along with fluorescence microscopy characterized the structure and fluidity of protein layers. (Reproduced with permission from [149], copyright 2007 American Chemical Society).

Accumulation of LPS in the blood can cause septic shock and, therefore, knowing the interaction of various components of LPS with the plasma membrane is of utmost importance [109]. Direct interaction of LPS molecules with the host cell membrane is mediated by hydrophobic interaction and binding with receptors and signal proteins gives rise to a cascade of reactions finally leading to observable biological effects. The non-specific interaction of lipid A from Salmonella Minnesota with phospholipid membranes has been studied using FTIR. Furthermore, lipopolysaccharide-binding protein (LBP) mediates the incorporation of LPS into cell membranes as determined from fluorescence resonance energy transfer (FRET) studies [150]. The interaction of LPS with the cell membrane does not depend upon its amphiphilic properties and charge polarization. Studies have shown that cation availability can induce changes in the supported lipid bilayer assemblies (SLBAs), for instance, LPS-Na ${ }^{+}$gives rise to long flexible lipid tubules from surface associated lipid vesicles whereas LPS-Ca ${ }^{2+}$ give rise to planar lipid sheets. The interaction studies are useful platforms to give us insight into how virulence factors affect humans [151].

Supported lipid bilayers are useful substrates for studying the interaction of amphiphilic molecules with biological membranes. Amphiphilic analytes when interacting with planar bilayers give rise to three-dimensional dynamic lipid structures such as lipid fibrils with a diameter near or below the limit of optical resolution. Lipid fibril extension is induced by binding LPS to SLBs through the packing stress-induced mechanism [152]. A topic covered only sparsely in the literature is the study of the interaction of host defense peptides and LPS and its consequential effect on membrane interactions. Interaction of antimicrobial peptide NK-2 and LPS has been studied and it was seen that hydrophobic interactions are necessary to curb the effect of LPS whereas electrostatic interactions are dominant when the binding is through carbohydrate chains of LPS [153]. Studies have been undertaken showing that the peptide polymyxin B interacts with the bio membrane model due to a charge-dependent effect and the interaction is not affected by the presence of LPS on the lipid vesicle composition [154]. Work has been done to develop an in vitro supported bilayer platform directly from outer membrane vesicles (OMVs) of E. coli that resembled the outer membrane of Gram-negative bacteria maintaining the native lipid and protein content along with the asymmetry of the membrane. The creation of OMVs 
has helped the researchers to study the changes in bacterial membrane mechanical properties during antibacterial action [155].

Several years ago, research related to the analysis of substance-induced shape changes in GUVs of lipid membranes was carried out and it was found that low concentration of single long chain amphiphiles such as lysophosphatidic acid (lyso-PA) induced reversible shape changes in the GUVs of sphingomyelin/cholesterol membranes in the liquid-ordered phase whereas higher concentrations lead to vesicle fissions of GUVs [156]. Exploiting the destabilization effect of lipopolysaccharides to generate voids in the membrane, researchers have used this strategy in creating hierarchically organized membrane domains and microscale 2-D array patterns of domains. This approach acts as a toolkit for bioengineered functional membrane design with potential applications for biosensing and investigating lipid-membrane processes [92].

\section{Conclusions}

In this review, we have summarized the different techniques used so far to create artificial lipid membrane models. We began our discussion by throwing some light on liposome fusion, monolayers at the air-water interface, LB-LS techniques, and other methods involving self-assembly. Over the past few years, biomimetic models of lipid membranes have been extensively worked upon involving tethered and hybrid systems, and various techniques such as AFM, QCM, and fluorescence spectroscopy have been used to fully characterize the formation process. The effect of various parameters such as type of substrate selected for the formation of SLB, lipid concentration in the organic solvent for vesicle formation, temperature, and the methodology employed have been seen to have had a pronounced effect on the membrane stability and structural features. Different strategies for creating an artificial membrane that closely resembled the biological membrane, have been discussed encompassing vesicle fusion, Langmuir-type techniques, self-spreading, and spin coating. Lipid monolayers at the air-water interface or on a solid support is a simplified reconstitution model of biological membranes that have now been extended to complex glycolipids such as LPS [105]. In this review, the formation of LPS monolayers along with their interaction with the biological membrane have been studied. Biophysical interaction studies with the model membranes have succeeded in giving a broader outlook about the changes happening upon the bacterial invasion of host cells or adhesion to surfaces during colonization of tissues. LPS, being an integral component of the bacterial outer membrane, has been employed for creating monolayers for a better understanding of the mechanisms of interactions that could provide a rational approach in the development drugs that target LPS and its interactions in diseases such as sepsis [146].

Funding: This research received no external funding.

Conflicts of Interest: The authors declare no conflict of interest.

\section{References}

1. Siontorou, C.G.; Nikoleli, G.P.; Nikolelis, D.P.; Karapetis, S.K. Artificial Lipid Membranes: Past, Present, and Future. Membranes 2017, 7, 38. [CrossRef] [PubMed]

2. Edidin, M. Lipids on the frontier: A century of cell-membrane bilayers. Nat. Rev. Mol. Cell Biol. 2003, 4, 414-418. [CrossRef] [PubMed]

3. Lind, T.K.; Cardenas, M. Understanding the formation of supported lipid bilayers via vesicle fusion-A case that exemplifies the need for the complementary method approach (Review). Biointerphases 2016, 11, 020801. [CrossRef] [PubMed]

4. Khan, M.S.; Dosoky, N.S.; Williams, J.D. Engineering lipid bilayer membranes for protein studies. Int. J. Mol. Sci. 2013, 14, 21561-21597. [CrossRef]

5. Mueller, P.; Rudin, D.O.; Tien, H.T.; Wescott, W.C. Methods for the formation of single bimolecular lipid membranes in aqueous solution. J. Phys. Chem. 1963, 67, 534-535. [CrossRef] 
6. Ross, C.; Bean, W.C.S.; Chan, H. Permeability of Lipid Bilayer Membranes to Organic Solutes. J. Gen. Physiol. 1968, 52, 495-508.

7. Gruner, S.M. Novel Multilayered Lipid Vesicles: Comparison of Physical Characteristics of Multilamellar Liposomes and Stable Plurilamellar Vesicles. Biochemistry 1985, 24, 2833-2842. [CrossRef]

8. Lombard, J. Once upon a time the cell membranes: 175 years of cell boundary research. Biol. Direct. 2014, 9, 32. [CrossRef]

9. Tamm, L.K.; McConnell, H.M. Supported phospholipid bilayers. Biophys. J. 1985, 47, 105-113. [CrossRef]

10. Murray, D.H.; Tamm, L.K.; Kiessling, V. Supported double membranes. J. Struct. Biol 2009, 168, $183-189$. [CrossRef] [PubMed]

11. Plant, A.L. Self-Assembled Phospholipid/Alkanethiol Biomimetic Bilayers on Gold. Langmuir 1993, 9, 2764-2767. [CrossRef]

12. Lang, H.; Duschl, C.; Vogel, H. A new class of thiolipids for the attachment of lipid bilayers on gold surfaces. Langmuir 1994, 10, 197-210. [CrossRef]

13. Groves, J.T.; Ulman, N.; Boxer, S.G. Micropatterning Fluid Lipid Bilayers on Solid Supports. Sci. Rep. 1997, 275, 651-653. [CrossRef]

14. Raguse, B.; Braach-Maksvytis, V.; Cornell, B.A.; King, L.G.; Osman, P.D.J.; Pace, R.J.; Wieczorek, L. Tethered Lipid Bilayer Membranes: Formation and Ionic Reservoir Characterization. Langmuir 1998, 14, 648-659. [CrossRef]

15. Oudenaarden, A.V.; Boxer, S.G. Brownian Ratchets: Molecular Separations in Lipid Bilayers Supported on Patterned Arrays. Science 1999, 285, 1046-1048. [CrossRef] [PubMed]

16. Sackmann, E.; Tanaka, M. Supported membranes on soft polymer cushions: Fabrication, characterization and applications. Trends Biotechnol. 2000, 18, 58-64. [CrossRef]

17. Mennicke, U.; Salditt, T. Preparation of Solid-Supported Lipid Bilayers by Spin-Coating. Langmuir 2002, 18, 8172-8177. [CrossRef]

18. Richard, C.; Balavoine, F.; Schultz, P.; Ebbesen, T.W.; Mioskowski, C. Supramolecular Self-Assembly of Lipid Derivatives on Carbon Nanotubes. Science 2003, 300, 775-778. [CrossRef] [PubMed]

19. Mornet, S.P.; Lambert, O.; Duguet, E.; Brisson, A. The Formation of Supported Lipid Bilayers on Silica Nanoparticles Revealed by Cryoelectron Microscopy. Nano Lett. 2005, 5, 281-285. [CrossRef]

20. Kalyankar, N.D.; Sharma, M.K.; Vaidya, S.V.; Calhoun, D.; Maldarelli, C.; Couzis, A.; Gilchrist, L. Arraying of Intact Liposomes into Chemically Functionalized Microwells. Langmuir 2006, 22, 5403-5411. [CrossRef]

21. Zhang, Y.; Chen, Y.; Jin, G. PEGylated phospholipid membrane on polymer cushion and its interaction with cholesterol. Langmuir 2010, 26, 11140-11144. [CrossRef] [PubMed]

22. Richter, R.P.; Berat, R.; Brisson, A.R. Formation of Solid-Supported Lipid Bilayers: An Integrated View. Langmuir 2006, 22, 3497-3505. [CrossRef] [PubMed]

23. Berti, D.; Caminati, G.; Baglioni, P. Functional liposomes and supported lipid bilayers: Towards the complexity of biological archetypes. Phys. Chem. Chem. Phys. 2011, 13, 8769-8782. [CrossRef] [PubMed]

24. Jass, J.; Tjarnhage, T.; Puu, G. From Liposomes to Supported, Planar Bilayer Structures on Hydrophilic and Hydrophobic Surfaces: An Atomic Force Microscopy Study. Biophys. J. 2000, 79, 3153-3163. [CrossRef]

25. Puu, G.; Gustafson, I. Planar lipid bilayers on solid supports from liposomes-factors of importance for kinetics and stability. Biochim. Biophys. Acta 1997, 1327, 149-161. [CrossRef]

26. Strauss, G.; Ingenito, E.P. Stabilization of Liposome Bilayers to Freezing and Thawing: Effects of Cryoprotective Agents and Membrane Proteins. Cryobiology 1980, 17, 508-515. [CrossRef]

27. Ye, Q.; Konradi, R.; Textor, M.; Reimhult, E. Liposomes tethered to omega-functional PEG brushes and induced formation of PEG brush supported planar lipid bilayers. Langmuir 2009, 25, 13534-13539. [CrossRef]

28. Kumar, K.; Isa, L.; Egner, A.; Schmidt, R.; Textor, M.; Reimhult, E. Formation of nanopore-spanning lipid bilayers through liposome fusion. Langmuir 2011, 27, 10920-10928. [CrossRef] [PubMed]

29. Jing, Y.; Trefna, H.; Persson, M.; Kasemo, B.; Svedhem, S. Formation of supported lipid bilayers on silica: Relation to lipid phase transition temperature and liposome size. Soft Matter 2014, 10, 187-195. [CrossRef] [PubMed]

30. McConnell, H.M.; Tamm, L.K.; Weis, R.M. Periodic structures in lipid monolayer phase transitions. Proc. Natl. Acad. Sci. USA 1984, 81, 3249-3253. [CrossRef]

31. von Tscharner, V.; McConnell, H.M. An alternative view of phospholipid phase behavior at the air-water interface. Microscope and film balance studies. Biophys. J. 1981, 36, 409-419. [CrossRef] 
32. Klopfer, K.J.; Vanderlick, T.K. Isotherms of Dipalmitoylphosphatidylcholine (DPPC) Monolayers: Features Revealed and Features Obscured. J. Colloid Interface Sci. 1996, 182, 220-229. [CrossRef]

33. Brown, R.E.; Brockman, H.L. Using Monomolecular Films to Characterize Lipid Lateral Interactions. In Lipid Rafts; McIntosh, T.J., Ed.; Humana Press: Totowa, NJ, USA, 2007; pp. 41-58.

34. Ali, S.; Smaby, J.M.; Brockman, H.L.; Brown, R.E. Cholesterol's interfacial interactions with galactosylceramides. Biochemistry 1994, 33, 2900-2906. [CrossRef] [PubMed]

35. Lee, K.Y.C.; McConnell, H.M. Quantized symmetry of liquid monolayer domains. J. Phys. Chem. 1993, 97, 9532-9539. [CrossRef]

36. Rice, P.A.; McConnell, H.M. Critical shape transitions of monolayer lipid domains. Proc. Natl. Acad. Sci. USA 1989, 86, 6445-6448. [CrossRef] [PubMed]

37. McConnell, H.M. Harmonic shape transitions in lipid monolayer domains. J. Phys. Chem. 1990, 94, 4728-4731. [CrossRef]

38. Ariga, K.; Hill, J.P. Monolayers at air-water interfaces: From origins-of-life to nanotechnology. Chem. Rec. 2011, 11, 199-211. [CrossRef] [PubMed]

39. David, V.; Kjaer, K.; Als-Nielsen, J.; Losche, M. Structural properties of phosphatidylcholine in a monolayer at the air/water interface. Biophys. J. 1991, 59, 1325-1332.

40. Tronin, A.; Dubrovsky, T.; Nicolini, C. Comparative study of Langmuir monolayers of immunoglobines G formed at the air-water interface and covalently immobilized on solid supports. Langmuir 1995, 11, 385-389. [CrossRef]

41. Faure, M.C.; Bassereau, P.; Carignano, M.A.; Szleifer, I.; Gallot, Y.; Andelman, D. Monolayers of diblock copolymer at the air-water interface: The attractive monomer-surface case. Eur. Phys. J. B 1998, 3, 365-375. [CrossRef]

42. Du, X.; Shi, B.; Liang, Y. N-Octadecanoyl-L-alanine Amphiphile Monolayer at the Air/Water Interface and LB Film Studied by FTIR Spectroscopy. Langmuir 1998, 14, 3631-3636. [CrossRef]

43. Nandi, N.; Vollhardt, D. Chiral discrimination and recognition in Langmuir monolayers. Curr. Opin. Colloid Interface Sci. 2008, 13, 40-46. [CrossRef]

44. Nandi, N.; Vollhardt, D. Effect of Molecular Chirality on the Morphology of Biomimetic Langmuir Monolayers. Chem. Rev. 2003, 103, 4033-4076. [CrossRef] [PubMed]

45. Michinobu, T.; Shinoda, S.; Nakanishi, T.; Hill, J.P.; Fujii, K.; Player, T.N.; Tsukube, H.; Ariga, K. Mechanical Control of Enantioselectivity of Amino Acid Recognition by Cholesterol-Armed Cyclen Monolayer at the Air-Water Interface. J. Am. Chem. Soc. 2006, 128, 14478-14479. [CrossRef] [PubMed]

46. Ebara, Y.; Okahata, Y. In Situ Surface-Detecting Technique by Using a Quartz-Crystal Microbalance. InteractionmBehaviors of Proteins onto a Phospholipid Monolayer at the Air-Water Interface. Langmuir 1993, 9, 574-576. [CrossRef]

47. Li, J.; Chen, Z.; Wang, X.; Brezesinski, G.; Mohwald, H. Dynamic observations of the hydrolysis of a DPPC monolayer at the air/water interface catalyzed by phospholipase A2. Angew. Chem. Int. Ed. 2000, 39, 3059-3062. [CrossRef]

48. Miao, W.; Du, X.; Liang, Y. Molecular Recognition of Nucleolipid Monolayers of 1-(2-Octadecyloxycarbonylethyl)cytosine to Guanosine at the Air-Water Interface and Langmuir-Blodgett Films. Langmuir 2003, 19, 5389-5396. [CrossRef]

49. Zhao, L.; Feng, S.S. Effects of cholesterol component on molecular interactions between paclitaxel and phospholipid within the lipid monolayer at the air-water interface. J. Colloid Interface Sci. 2006, 300, 314-326. [CrossRef]

50. Chen, Q.; Zhang, D.; Li, R.; Liu, H.; Hu, Y. Effect of the spacer group on the behavior of the cationic Gemini surfactant monolayer at the air/water interface. Thin Solid Films 2008, 516, 8782-8787. [CrossRef]

51. Chen, Q.; Kang, X.; Li, R.; Du, X.; Shang, Y.; Liu, H.; Hu, Y. Structure of the complex monolayer of gemini surfactant and DNA at the air/water interface. Langmuir 2012, 28, 3429-3438. [CrossRef]

52. Jyoti, A.; Prokop, R.M.; Li, J.; Vollhardt, D.; Kwok, D.Y.; Miller, R.; Mohwald, H.; Neumann, A.W. An investigation of the compression rate dependence on the surface pressure-surface area isotherm for a dipalmitoyl phosphatidylcholine monolayer at the air/water interface. Colloids Surf. A Physicochem. Eng. Asp. 1996, 173-180. [CrossRef]

53. Patino, J.M.R.; Sanchez, C.C.; Nino, M.R.R. Structural and morphological characteristics of beta-casein monolayers at the air-water interface. Food Hydrocoll. 1999, 13, 401-408. [CrossRef] 
54. Ma, G.; Allen, H.C. DPPC Langmuir Monolayer at the Air-Water Interface: Probing the Tail and Head Groups by Vibrational Sum Frequency Generation Spectroscopy. Langmuir 2006, 22, 5341-5349. [CrossRef] [PubMed]

55. Dufrêne, Y.F.; Lee, G.U. Advances in the characterization of supported lipid films with the atomic force microscope. Biochim. Biophys. Acta Biomembr. 2000, 1509, 14-41. [CrossRef]

56. Kurniawan, J.; Ventrici de Souza, J.F.; Dang, A.T.; Liu, G.-Y.; Kuhl, T.L. Preparation and Characterization of Solid-Supported Lipid Bilayers Formed by Langmuir-Blodgett Deposition: A Tutorial. Langmuir 2018, 34, 15622-15639. [CrossRef]

57. Blodgett, K.B.; Langmuir, I. Built-up films of barium stearate and their optical properties. Phys. Rev. 1937, 51, 964-982. [CrossRef]

58. Cea, P.; Ballesteros, L.M.; Martín, S. Nanofabrication techniques of highly organized monolayers sandwiched between two electrodes for molecular electronics. Nanofabrication 2014, 1, 96-117. [CrossRef]

59. Rojewska, M.; Skrzypiec, M.; Prochaska, K. The wetting properties of Langmuir-Blodgett and Langmuir-Schaefer films formed by DPPC and POSS compounds. Chem. Phys. Lipids 2019, 221, 158-166. [CrossRef]

60. Marfin, Y.S.; Usoltsev, S.D.; Kazak, A.V.; Smirnova, A.I.; Rumyantsev, E.V.; Molchanov, E.E.; Kuznetsov, V.V.; Chumakov, A.S.; Glukhovskoy, E.G. Synthesis and spectral properties of preorganized BODIPYs in solutions and Langmuir-Schaefer films. Appl. Surf. Sci. 2017, 424, 228-238. [CrossRef]

61. Stottrup, B.L.; Veatch, S.L.; Keller, S.L. Nonequilibrium Behavior in Supported Lipid Membranes Containing Cholesterol. Biophys. J. 2004, 86, 2942-2950. [CrossRef]

62. Deverall, M.A.; Gindl, E.; Sinner, E.K.; Besir, H.; Ruehe, J.; Saxton, M.J.; Naumann, C.A. Membrane lateral mobility obstructed by polymer-tethered lipids studied at the single molecule level. Biophys. J. 2005, 88, 1875-1886. [CrossRef] [PubMed]

63. Clifton, L.A.; Skoda, M.W.; Daulton, E.L.; Hughes, A.V.; Le Brun, A.P.; Lakey, J.H.; Holt, S.A. Asymmetric phospholipid: Lipopolysaccharide bilayers; a Gram-negative bacterial outer membrane mimic. J. $R$ Soc. Interface 2013, 10, 1-11. [CrossRef]

64. Clifton, L.A.; Holt, S.A.; Hughes, A.V.; Daulton, E.L.; Arunmanee, W.; Heinrich, F.; Khalid, S.; Jefferies, D.; Charlton, T.R.; Webster, J.R.; et al. An accurate in vitro model of the E. coli envelope. Angew. Chem. Int. Ed. Engl. 2015, 54, 11952-11955. [CrossRef]

65. Clifton, L.A.; Ciesielski, F.; Skoda, M.W.; Paracini, N.; Holt, S.A.; Lakey, J.H. The Effect of Lipopolysaccharide Core Oligosaccharide Size on the Electrostatic Binding of Antimicrobial Proteins to Models of the Gram Negative Bacterial Outer Membrane. Langmuir 2016, 32, 3485-3494. [CrossRef]

66. Riegler, H.; Spratte, K. Structural changes in lipid monolayers during the Langmuir-Blodgett transfer due to substrate/monolayer interactions. Thin Solid Films 1992, 210-211, 9-12. [CrossRef]

67. Simonsen, A.C.; Bagatolli, L.A. Structure of Spin-Coated Lipid Films and Domain Formation in Supported Membranes Formed by Hydration. Langmuir 2004, 20, 9720-9728. [CrossRef] [PubMed]

68. Dols-Perez, A.; Fumagalli, L.; Simonsen, A.C.; Gomila, G. Ultrathin spin-coated dioleoylphosphatidylcholine lipid layers in dry conditions: A combined atomic force microscopy and nanomechanical study. Langmuir 2011, 27, 13165-13172. [CrossRef]

69. Krapf, L.; Dezi, M.; Reichstein, W.; Kohler, J.; Oellerich, S. AFM characterization of spin-coated multilayered dry lipid films prepared from aqueous vesicle suspensions. Colloids Surf. B 2011, 82, 25-32. [CrossRef] [PubMed]

70. Hardy, G.J.; Nayak, R.; Zauscher, S. Model cell membranes: Techniques to form complex biomimetic supported lipid bilayers via vesicle fusion. Curr. Opin. Colloid Interface Sci. 2013, 18, 448-458. [CrossRef]

71. Lind, T.K.; Cárdenas, M.; Wacklin, H.P. Formation of Supported Lipid Bilayers by Vesicle Fusion: Effect of Deposition Temperature. Langmuir 2014, 30, 7259-7263. [CrossRef] [PubMed]

72. Jackman, J.A.; Cho, N.-J. Supported Lipid Bilayer Formation: Beyond Vesicle Fusion. Langmuir 2020, 36, 1387-1400. [CrossRef] [PubMed]

73. Hamai, C.; Yang, T.; Kataoka, S.; Cremer, P.S.; Musser, S.M. Effect of Average Phospholipid Curvature on Supported Bilayer Formation on Glass by Vesicle Fusion. Biophys. J. 2006, 90, 1241-1248. [CrossRef] [PubMed]

74. Pace, H.; Simonsson, N.L.; Gunnarsson, A.; Eck, E.; Monson, C.; Geschwindner, S.; Snijder, A.; Höök, F. Preserved Transmembrane Protein Mobility in Polymer-Supported Lipid Bilayers Derived from Cell Membranes. Anal. Chem. 2015, 87, 9194-9203. [CrossRef] [PubMed] 
75. Tabaei, S.R.; Choi, J.-H.; Haw Zan, G.; Zhdanov, V.P.; Cho, N.-J. Solvent-Assisted Lipid Bilayer Formation on Silicon Dioxide and Gold. Langmuir 2014, 30, 10363-10373. [CrossRef]

76. Gillissen, J.J.J.; Tabaei, S.R.; Cho, N.-J. A phenomenological model of the solvent-assisted lipid bilayer formation method. Phys. Chem. Chem. Phys. 2016, 18, 24157-24163. [CrossRef]

77. Furukawa, K.; Hibino, H. Self-spreading of Supported Lipid Bilayer on $\mathrm{SiO}_{2}$ Surface Bearing Graphene Oxide. Chem. Lett. 2012, 41, 1259-1261. [CrossRef]

78. Benes, M.; Billy, D.; Benda, A.; Speijer, H.; Hof, M.; Hermens, W.T. Surface-Dependent Transitions during Self-Assembly of Phospholipid Membranes on Mica, Silica, and Glass. Langmuir 2004, 20, 10129-10137. [CrossRef] [PubMed]

79. Mundev, D.; Turyan, I. Applications of Self-Assembled Monolayers in Electroanalytical Chemistry. Electroanalysis 1996, 8, 207-213.

80. Cremer, P.S.; Boxer, S.G. Formation and Spreading of Lipid Bilayers on Planar Glass Supports. J. Phys. Chem. B 1999, 103, 2554-2559. [CrossRef]

81. Peng, Z.; Shimba, K.; Miyamoto, Y.; Yagi, T. Nanopore lipid bilayer formed by self-spreading method. Electron. Commun. Jpn. 2019, 102, 47-54. [CrossRef]

82. Furukawa, K.; Sumitomo, K.; Nakashima, H.; Kashimura, Y.; Torimitsu, K. Supported Lipid Bilayer Self-Spreading on a Nanostructured Silicon Surface. Langmuir 2007, 23, 367-371. [CrossRef] [PubMed]

83. Park, J.Y.; Advincula, R.C. Nanostructuring polymers, colloids, and nanomaterials at the air-water interface through Langmuir and Langmuir-Blodgett techniques. Soft Matter 2011, 7, 9829-9843. [CrossRef]

84. Gidalevitz, D.; Huang, Z.; Rice, S.A. Protein folding at the air-water interface studied with x-ray reflectivity. Proc. Natl. Acad. Sci. USA 1999, 96, 2608-2611. [CrossRef]

85. Biswas, S.; Bhattacharjee, D.; Nath, R.K.; Hussain, S.A. Formation of complex Langmuir and Langmuir-Blodgett films of water soluble rosebengal. J. Colloid Interface Sci. 2007, 311, 361-367. [CrossRef] [PubMed]

86. Savva, M.; Sivakumar, B.; Selvi, B. The Conventional Langmuir Trough Technique as a Convenient Means to Determine the Solubility of Sparingly Soluble Surface Active Molecules: Case Study Cholesterol. Colloids Surf. A Physicochem. Eng. Asp. 2008, 325, 1-6. [CrossRef]

87. Nie, H.-L.; Dou, X.; Tang, Z.; Jang, H.D.; Huang, J. High-Yield Spreading of Water-Miscible Solvents on Water for Langmuir-Blodgett Assembly. J. Am. Chem. Soc. 2015, 137, 10683-10688. [CrossRef]

88. Chan, Y.-H.M.; Boxer, S.G. Model membrane systems and their applications. Curr. Opin. Chem. Biol. 2007, 11, 581-587. [CrossRef]

89. Yeung, S.Y.; Ederth, T.; Pan, G.; Cicenaite, J.; Cárdenas, M.; Arnebrant, T.; Sellergren, B.r. Reversible Self-Assembled Monolayers (rSAMs) as Robust and Fluidic Lipid Bilayer Mimics. Langmuir 2018, 34, 4107-4115. [CrossRef]

90. Andersson, J.; Köper, I.; Knoll, W. Tethered Membrane Architectures-Design and Applications. Front. Mater. 2018, 5, 55. [CrossRef]

91. Glazier, R.; Salaita, K. Supported lipid bilayer platforms to probe cell mechanobiology. Biochim. Biophys. Acta Biomembr. 2017, 1859, 1465-1482. [CrossRef]

92. Adams, P.G.; Swingle, K.L.; Paxton, W.F.; Nogan, J.J.; Stromberg, L.R.; Firestone, M.A.; Mukundan, H.; Montaño, G.A. Exploiting lipopolysaccharide-induced deformation of lipid bilayers to modify membrane composition and generate two-dimensional geometric membrane array patterns. Sci. Rep. 2015, 5, 10331. [CrossRef] [PubMed]

93. Kaeothip, S.; Paranjape, G.; Terrill, S.E.; Bongat, A.F.G.; Udan, M.L.D.; Kamkhachorn, T.; Johnson, H.L.; Nichols, M.R.; Demchenko, A.V. Development of LPS antagonistic therapeutics: Synthesis and evaluation of glucopyranoside-spacer-amino acid motifs. RSC Adv. 2011, 1, 83-92. [CrossRef]

94. Jeworrek, C.; Evers, F.; Howe, J.; Brandenburg, K.; Tolan, M.; Winter, R. Effects of specific versus nonspecific ionic interactions on the structure and lateral organization of lipopolysaccharides. Biophys. J. 2011, 100, 2169-2177. [CrossRef] [PubMed]

95. Le Brun, A.P.; Clifton, L.A.; Halbert, C.E.; Lin, B.; Meron, M.; Holden, P.J.; Lakey, J.H.; Holt, S.A. Structural characterization of a model gram-negative bacterial surface using lipopolysaccharides from rough strains of Escherichia coli. Biomacromolecules 2013, 14, 2014-2022. [CrossRef] [PubMed] 
96. Ferguson, A.D.; Welte, W.; Hofmann, E.; Lindner, B.; Holst, O.; Coulton, J.W.; Diederichs, K. A conserved structural motif for lipopolysaccharide recognition by procaryotic and eucaryotic proteins. Structure 2000, 8, 585-592. [CrossRef]

97. Hong-bao, M.; Ma, M.; Yan, Y. Lipopolysaccharide (LPS) and Hypoxia Inducible Factor (HIF)-1alpha Research literatures. Rep. Opin. 2015, 7, 93-112.

98. Nepal, B.; Stine, K.J. Monolayers of Carbohydrate-Containing Lipids at the Water-Air Interface. In Cell Culture; Radwa, A.M., Ed.; BoD—Books on Demand: London, UK, 2018; pp. 213-241.

99. Abraham, T.; Schooling, S.R.; Beveridge, T.J.; Katsaras, J. Monolayer Film Behavior of Lipopolysaccharide from Pseudomonas aeruginosa at the Air-Water Interface. Biomacromolecules 2008, 9, 2799-2804. [CrossRef] [PubMed]

100. Neter, E.; Westphal, O.; Lüderitz, O.; Gorzynski, E.A.; Eichenberger, E. Studies of Enterobacterial Lipopolysaccharides. Effects of Heat and Chemicals on Erythrocyte-Modifying, Antigenic, Toxic and Pyrogenic Properties. J. Immunol. 1956, 76, 377-385. [PubMed]

101. Neter, E.; Gorzynski, E.A.; Westphal, O.; Lüderitz, O. The Effects of Antibiotics on Enterobacterial Lipopolysaccharides (Endotoxins), Hemagglutination and Hemolysis. J. Immunol. 1958, 80, 66-72.

102. Rothfield, L.; Horne, R.W. Reassociation of Purified Lipopolysaccharide and Phospholipid of the Bacterial Cell Envelope: Electron Microscopic and Monolayer Studies. J. Bacteriol. 1967, 93, 1705-1721. [CrossRef] [PubMed]

103. Shands, J.J.; Graham, J.; Nath, K. The morphologic structure of isolated bacterial lipopolysaccharide. J. Mol. Biol. 1967, 25, 15-21. [CrossRef]

104. Romeo, D.; Girard, A.; Rothfield, L. Reconstitution of a functional membrane enzyme system in a monomolecular film: I. Formation of a mixed monolayer of lipopolysaccharide and phospholipid. J. Mol. Biol. 1970, 53, 475-490. [CrossRef]

105. Roes, S.; Seydel, U.; Gutsmann, T. Probing the Properties of Lipopolysaccharide Monolayers and Their Interaction with the Antimicrobial Peptide Polymyxin B by Atomic Force Microscopy. Langmuir 2005, 21, 6970-6978. [CrossRef]

106. Derde, M.; Nau, F.; Lechevalier, V.; Guerin-Dubiard, C.; Paboeuf, G.; Jan, S.; Baron, F.; Gautier, M.; Vie, V. Native lysozyme and dry-heated lysozyme interactions with membrane lipid monolayers: Lateral reorganization of LPS monolayer, model of the Escherichia coli outer membrane. Biochim. Biophys. Acta 2015, 1848, 174-183. [CrossRef] [PubMed]

107. Clifton, L.A.; Skoda, M.W.; Le Brun, A.P.; Ciesielski, F.; Kuzmenko, I.; Holt, S.A.; Lakey, J.H. Effect of divalent cation removal on the structure of gram-negative bacterial outer membrane models. Langmuir 2015, 31, 404-412. [CrossRef]

108. Micciulla, S.; Gerelli, Y.; Schneck, E. Structure and Conformation of Wild-Type Bacterial Lipopolysaccharide Layers at Air-Water Interfaces. Biophys. J. 2019, 116, 1259-1269. [CrossRef]

109. Sondhi, P.; Maruf, M.H.U.; Stine, K.J. Nanomaterials for Biosensing Lipopolysaccharide. Biosensors 2019, 10, 2. [CrossRef] [PubMed]

110. Carotovora, E.; Fukuoka, S.; Brandenburg, K.; Muller, M.; Lindner, B.; Koch, M.H.J.; Seydel, U. Physico-chemical analysis of lipid A fractions of lipopolysaccharide from Erwinia carotovora in relation to bioactivity. Biochim. Biophys. Acta 2001, 1510, 185-197.

111. Yu, Z.-W.; Jin, J.; Cao, Y. Characterization of the liquid-expanded to liquid-condensed phase transition of monolayers by means of compressibility. Langmuir 2002, 18, 4530-4531. [CrossRef]

112. Seydel, U.; Oikawa, M.; Fukase, K.; Kusumoto, S.; Brandenburg, K. Intrinsic conformation of lipid A is responsible for agonistic and antagonistic activity. Eur. J. Biochem. 2000, 267, 3032-3039. [CrossRef]

113. Luderitz, O.; Staub, A.M.; Westphal, O. Immunochemistry of 0 and R Antigens of Salmonella and Related Enterobacteriaceae. Bacteriol. Rev. 1966, 30, 192-255. [CrossRef]

114. Parikh, A.N.; Groves, J.T. Materials Science of Supported Lipid Membranes. MRS Bull. 2011, 31, 507-512. [CrossRef]

115. Pompeo, G.; Girasole, M.; Cricenti, A.; Cattaruzza, F.; Flamini, A.; Prosperi, T.; Generosi, J.; Castellano, A.C. AFM characterization of solid-supported lipid multilayers prepared by spin-coating. Biochim. Biophys. Acta 2005, 1712, 29-36. [CrossRef] [PubMed] 
116. Hianik, T.; Haburcak, M.; Lohner, K.; Prenner, E.; Paltauf, F.; Hermetter, A. Compressibility and density of lipid bilayers composed of polyunsaturated phospholipids and cholestrol. Colloids Surf. Physicochem. Eng. Asp. 1998, 139, 189-197. [CrossRef]

117. Radler, J.; Strey, H.; Sackmann, E. Phenomenology and kinetis of lipid bilayer spreading on hydrophilic surfaces. Langmuir 1995, 11, 4539-4548. [CrossRef]

118. Honigmann, A.; Mueller, V.; Hell, S.W.; Eggeling, C. STED microscopy detects and quantifies liquid phase separation in lipid membranes using a new far-red emitting fluorescent phosphoglycerolipid analogue. Faraday Discuss. 2013, 161, 77-89. [CrossRef] [PubMed]

119. Honigmann, A.; Mueller, V.; Ta, H.; Schoenle, A.; Sezgin, E.; Hell, S.W.; Eggeling, C. Scanning STED-FCS reveals spatiotemporal heterogeneity of lipid interaction in the plasma membrane of living cells. Nat. Commun. 2014, 5, 5412. [CrossRef]

120. Tero, R. Substrate Effects on the Formation Process, Structure and Physicochemical Properties of Supported Lipid Bilayers. Materials 2012, 5, 2658-2680. [CrossRef]

121. Huang, C.-J.; Chang, Y.-C. Construction of Cell-Extracellular Matrix Microenvironments by Conjugating ECM Proteins on Supported Lipid Bilayers. Front. Mater. 2019, 6, 39. [CrossRef]

122. Subczynski, W.K.; Wisniewska, A. Physical properties of lipid bilayer membranes: Relevance to membrane biological functions. Acta Biochim. Pol. 2000, 47, 613-625. [CrossRef] [PubMed]

123. Howland, M.C.; Szmodis, A.W.; Sanii, B.; Parikh, A.N. Characterization of physical properties of supported phospholipid membranes using imaging ellipsometry at optical wavelengths. Biophys. J. 2007, 92, 1306-1317. [CrossRef] [PubMed]

124. Janmey, P.A.; Kinnunen, P.K. Biophysical properties of lipids and dynamic membranes. Trends Cell Biol. 2006, 16, 538-546. [CrossRef] [PubMed]

125. Lind, T.K.; Skoda, M.W.; Cárdenas, M. Formation and characterization of supported lipid bilayers composed of phosphatidylethanolamine and phosphatidylglycerol by vesicle fusion, a simple but relevant model for bacterial membranes. ACS Omega 2019, 4, 10687-10694. [CrossRef] [PubMed]

126. Stahelin, R.V. Surface plasmon resonance: A useful technique for cell biologists to characterize biomolecular interactions. Mol. Biol. Cell 2013, 24, 883-886. [CrossRef]

127. Rossi, C.; Chopineau, J. Biomimetic tethered lipid membranes designed for membrane-protein interaction studies. Eur. Biophys. J. 2007, 36, 955-965. [CrossRef]

128. Kiselev, M.A.; Lombardo, D. Structural characterization in mixed lipid membrane systems by neutron and X-ray scattering. Biochim. Biophys. Acta Gen. Subj. 2017, 1861, 3700-3717. [CrossRef]

129. Sut, T.N.; Park, S.; Choe, Y.; Cho, N.-J. Characterizing the Supported Lipid Membrane Formation from Cholesterol-Rich Bicelles. Langmuir 2019, 35, 15063-15070. [CrossRef]

130. Khan, M.S.; Dosoky, N.S.; Patel, D.; Weimer, J.; Williams, J.D. Lipid Bilayer Membrane in a Silicon Based Micron Sized Cavity Accessed by Atomic Force Microscopy and Electrochemical Impedance Spectroscopy. Biosensors 2017, 7, 26. [CrossRef]

131. Clausen, M.P.; Sezgin, E.; Bernardino de la Serna, J.; Waithe, D.; Lagerholm, B.C.; Eggeling, C. A straightforward approach for gated STED-FCS to investigate lipid membrane dynamics. Methods 2015, 88, 67-75. [CrossRef]

132. Sezgin, E.; Levental, I.; Mayor, S.; Eggeling, C. The mystery of membrane organization: Composition, regulation and roles of lipid rafts. Nat. Rev. Mol. Cell Biol. 2017, 18, 361-374. [CrossRef]

133. Chung, M.; Boxer, S.G. Stability of DNA-Tethered Lipid Membranes with Mobile Tethers. Langmuir 2011, 27, 5492-5497. [CrossRef] [PubMed]

134. Giess, F.; Friedrich, M.G.; Heberle, J.; Naumann, R.L.; Knoll, W. The protein-tethered lipid bilayer: A novel mimic of the biological membrane. Biophys. J. 2004, 87, 3213-3220. [CrossRef] [PubMed]

135. Ragaliauskas, T.; Mickevicius, M.; Rakovska, B.; Penkauskas, T.; Vanderah, D.J.; Heinrich, F.; Valincius, G. Fast formation of low-defect-density tethered bilayers by fusion of multilamellar vesicles. Biochim. Biophys. Acta Biomembr. 2017, 1859, 669-678. [CrossRef] [PubMed]

136. Lee, B.K.; Lee, H.Y.; Kim, P.; Suh, K.Y.; Kawai, T. Nanoarrays of tethered lipid bilayer rafts on poly(vinyl alcohol) hydrogels. Lab Chip 2009, 9, 132-139. [CrossRef] [PubMed]

137. Krishna, G.; Schulte, J.; Cornell, B.A.; Pace, R.J.; Osman, P.D. Tethered Bilayer Membranes Containing Ionic Reservoirs: Selectivity and Conductance. Langmuir 2003, 19, 2294-2305. [CrossRef] 
138. Keizer, H.M.; Dorvel, B.R.; Andersson, M.; Fine, D.; Price, R.B.; Long, J.R.; Dodabalapur, A.; Koper, I.; Knoll, W.; Anderson, P.A.; et al. Functional ion channels in tethered bilayer membranes-implications for biosensors. Chembiochem. 2007, 8, 1246-1250. [CrossRef] [PubMed]

139. Maccarini, M.; Watkins, E.B.; Stidder, B.; Alcaraz, J.P.; Cornell, B.A.; Martin, D.K. Nanostructural determination of a lipid bilayer tethered to a gold substrate. Eur. Phys. J. E Soft Matter 2016, 39, 123-131. [CrossRef]

140. Rebaud, S.; Maniti, O.; Girard-Egrot, A.P. Tethered bilayer lipid membranes (tBLMs): Interest and applications for biological membrane investigations. Biochimie 2014, 107, 135-142. [CrossRef] [PubMed]

141. Penkauskas, T.; Preta, G. Biological applications of tethered bilayer lipid membranes. Biochimie 2019, 157, 131-141. [CrossRef]

142. Jackman, J.; Knoll, W.; Cho, N.-J. Biotechnology Applications of Tethered Lipid Bilayer Membranes. Materials 2012, 5, 2637-2657. [CrossRef]

143. Chan, Y.-H.M.; van Lengerich, B.; Boxer, S.G. Effects of linker sequences on vesicle fusion mediated by lipid-anchored DNA oligonucleotides. Proc. Natl. Acad. Sci. USA 2009, 106, 979-984. [CrossRef]

144. Andersson, J.; Köper, I. Tethered and Polymer Supported Bilayer Lipid Membranes: Structure and Function. Membranes 2016, 6, 30. [CrossRef] [PubMed]

145. Naumann, C.A.; Prucker, O.; Lehmann, T.; Rühe, J.; Knoll, W.; Frank, C.W. The Polymer-Supported Phospholipid Bilayer: Tethering as a New Approach to Substrate-Membrane Stabilization. Biomacromolecules 2002, 3, 27-35. [CrossRef] [PubMed]

146. Peetla, C.; Stine, A.; Labhasetwa, V. Biophysical Interactions with Model Lipid Membranes: Applications in Drug Discovery and Drug Deliver. Mol. Pharm. 2009, 6, 1264-1276. [CrossRef]

147. Marques, J.T.; Viana, A.S.; de Almeida, R.F. A biomimetic platform to study the interactions of bioelectroactive molecules with lipid nanodomains. Langmuir 2014, 30, 12627-12637. [CrossRef] [PubMed]

148. Morandat, S.; Kirat, K.E. Exploring the Properties and Interactions of Supported Lipid Bilayers on the Nanoscale by Atomic Force Microscopy. Microsc. Sci. Technol. Appl. Educ. 2010, 4, 1925-1939.

149. Horton, M.R.; Reich, C.; Gast, A.P.; Radler, J.O.; Nickel, B. Structure and Dynamics of Crystalline Protein Layers Bound to Supported Lipid Bilayers. Langmuir 2007, 23, 6263-6269. [CrossRef]

150. Gutsmann, T.; Schromm, A.B.; Koch, M.H.J.; Kusumoto, S.; Fukase, K.; Oikawa, M.; Seydel, U.; Brandenburg, K. Lipopolysaccharide-binding protein-mediated interaction of lipid A from different origin with phospholipid membranes. Phys. Chem. Chem. Phys. 2000, 2, 4521-4528. [CrossRef]

151. Stromberg, L.R. Differential Interactions of Lipopolysaccharides with Lipid Bilayers: Applications for pathogen detection. Ph.D. Thesis, The University of New Mexico Albuquerque, Albuquerque, NM, USA, 2016.

152. Kataoka-Hamai, C.; Kaizuka, Y.; Taguchi, T. Binding of Lipopolysaccharide and Cholesterol-Modified Gelatin on Supported Lipid Bilayers: Effect of Bilayer Area Confinement and Bilayer Edge Tension. Langmuir 2016, 32, 1250-1258. [CrossRef]

153. Singh, S.; Kasetty, G.; Schmidtchen, A.; Malmsten, M. Membrane and lipopolysaccharide interactions of C-terminal peptides from S1 peptidases. Biochim. Biophys. Acta 2012, 1818, 2244-2251. [CrossRef]

154. Domingues, M.M.; Inacio, R.G.; Raimundo, J.M.; Martins, M.; Castanho, M.A.; Santos, N.C. Biophysical characterization of polymyxin B interaction with LPS aggregates and membrane model systems. Biopolymers 2012, 98, 338-344. [CrossRef] [PubMed]

155. Hsia, C.-Y.; Chen, L.; Singh, R.R.; DeLisa, M.P.; Daniel, S. A Molecularly Complete Planar Bacterial Outer Membrane Platform. Sci. Rep. 2016, 6, 32715. [CrossRef] [PubMed]

156. Alam, J.M.; Yamazaki, M. Spontaneous insertion of lipopolysaccharide into lipid membranes from aqueous solution. Chem. Phys. Lipids 2011, 164, 166-174. [CrossRef]

Publisher's Note: MDPI stays neutral with regard to jurisdictional claims in published maps and institutional affiliations.

(C) 2020 by the authors. Licensee MDPI, Basel, Switzerland. This article is an open access article distributed under the terms and conditions of the Creative Commons Attribution (CC BY) license (http://creativecommons.org/licenses/by/4.0/). 